\title{
IX Congreso de Anatomía del Cono Sur XXIII Congresso Brasileiro de Anatomia XI Congresso Luso-Brasileiro de Anatomia XXVIII Congreso Chileno de Anatomía
}

\author{
19-23 de octubre de 2008
}

Hangar - Centro de Convenções e Feiras da Amazônia Av. Dr. Freitas, s/n0. Belém-Pará-Brasil.

\section{"Anatomia na Amazônia: Inovar para preservar a vida"}

\section{Entidades Promotoras:}

Sociedade Brasileira de Anatomia (SBA), Sociedade Luso-Brasileira de Anatomia (SLBA) y Sociedad Chilena de Anatomía (SCHA)

\section{Entidades Organizadoras:}

Universidade do Estado do Pará (UEPA) Universidade Federal do Pará (UFPa) Universidade Rural da Amazônia (Ufra) Centro Universitário do Pará (Cesupa) Universidade da Amazônia (UNAMA)
Presidente de los Congresos:

XXIII Congresso Brasileiro de Anatomia e XI Congresso Luso-Brasileiro de Anatomia.

Prof. Dr. Robson José de Sousa Domingues

IX Congreso de Anatomía del Cono Sur y XXVIII Congreso Chileno de Anatomía.

Prof. Dr. Mariano Guillermo del Sol Calderón

Presidentes de las Sociedades Científicas:

Sociedade Brasileira de Anatomia

Prof. Dr. Richard Halti Cabral

Sociedad Chilena de Anatomía Prof. Dr. Mariano Guillermo del Sol Calderón 
ACCURACY OF PALATE SHAPE LIKE SEX INDICATOR IN HUMAN SKULL WITH MAXILLARY TEETH LOSS. Exactitud de la forma del paladar como indicador de sexo en cráneos humanos con pérdida de dientes maxilares. Suazo G.I.C 1, 2; Zavando M.D.A1; Smith R.L2. 1Departamento de Anatomía Normal, Universidad de Talca. 2Departamento de Morfología y Genética. Universidad Federal de Sao Paulo, Brasil.

En medicina forense el diagnóstico del sexo es el primer paso para la identificación de cráneos humanos completos o incompletos. Para ello una primera aproximación se realiza mediante el análisis cualitativo de una serie de indicadores morfológicos de dimorfismo sexual. En estudios clásicos Krogman (1955) describió 14 indicadores que permitirían el diagnóstico del sexo con una exactitud del $90 \%$. Uno de estos indicadores es la forma del paladar, en este estudio se analizó la exactitud y sensibilidad de la forma del paladar como indicador de sexo en cráneos humanos brasileros con diferentes grados de pérdida de piezas dentarias maxilares. Se utilizaron 98 cráneos de individuos adultos brasileros con una edad media de 39.3 años (SD 7.8), 35 mujeres y 63 hombres. Los cráneos fueron clasificados en dos grupos, uno desdentado completo maxilar y otro desdentado parcial, un criterio de inclusión en el grupo de desdentados parciales fue la presencia de los caninos maxilares o de sus alveolos. La exactitud para el diagnóstico del sexo en la muestra total fue del $75.5 \%$ (Con una sensibilidad de $88.8 \%$ para hombres y de $51.5 \%$ para mujeres), la exactitud fue levemente mayor en el grupo de desdentados con un $76.9 \%$, con una sensibilidad de $84 \%$ para hombres y $70 \%$ para mujeres; mientras que el grupo de cráneos desdentados parciales presentó valores inferiores de exactitud, con un $74.5 \%$, y una sensibilidad del $90 \%$ para hombres y del $26 \%$ para mujeres. Este trabajo permite concluir que el edentulismo total no afecta considerablemente la exactitud del diagnóstico del sexo, pero la presencia de piezas dentarias favorece la subestimación de las mujeres al observar éste parámetro.

Palabras clave: Dimorfismo sexual; Determinación del sexo; paladar; pérdida dentaria.

\section{ALTERATIONS OF DENTAL ANATOMY INTERFERE} WITH THE ENDODONTIC TREATMENT. Lins,

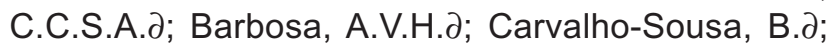

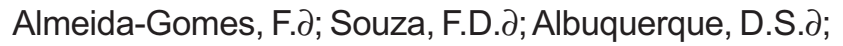

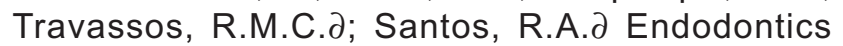
Departament, UPE-FOP, Recife, Pernambuco, Brazil.
I The alterations of dental anatomy can happen due to the physiological process of formation of the dental organ (alterations of development), as well as the dynamic of the answer of dental tissues due to injuries of all kind, like microbe, chemical and/or traumatic agents (pathological alterations). Some of these alterations cannot be clinically visualized, so the radiographic exam is a relevant helpful method to the diagnostic of the present anatomical modification. This work aims to realize an accurate approach by periapical radiographies of four kinds of anatomical alterations: gemination, "dens in dent", calcification and dilaceration, from patients which came to the Clinic of Curse the Endodontics Especialization Faculdade de Odontologia de Pernambuco - University of Pernambuco, in the year of 2007. It will be emphasized the etiology, the diagnostic, the clinical and radiographic characteristics of root anatomy, as well as the endodontic therapy. This way, it is important to emphasize the need of an accurate study of dental anatomy previous to the endodontic intervention, once the planning of the treatment that will be realized is crucial to the solution of the cases and consequently the success of the treatment, contributing to keep the tooth in the buccal cavity.

\section{ANÁLISE QUANTITATIVA COMPARATIVA DOS NEURÔNIOS DO JEJUNO DE RATOS WISTAR ENVELHECIDOS E SUPLEMENTADOS COM ÁCI- DO ASCÓRBICO. Buzzo Romano, Evanilde; Marçal Natali; Maria Raquel; Beraldi, Evandro José; Brites, Lílian; Carvalho, Joici (Universidade Estadual de Maringá (UEM) PR). Universidade Estadual de Maringá (UEM)}

O sistema nervoso entérico (SNE) consiste dos plexos ganglionados, mioentérico e submucoso, com localização intramural e se localiza em todo o trato gastrointestinal. Está conectado com o sistema nervoso central pela inervação extrínseca, consistindo de nervos simpáticos e parassimpáticos. Por meio destas conexões neurais, informações são transmitidas para o gânglio pré-paravertebral, a medula espinhal e por fim o cérebro. Como o envelhecimento é um processo natural que ocorre no trato gastrointestinal, provoca alterações no número e tamanho dos neurônios do (SNE). Ocorrendo, portanto, estresse oxidativo que produz os radicais livres que são, normalmente, neutralizados por sistemas eficientes no corpo, inclusive por moléculas como o ácido ascórbico. Portanto, a ação dos radicais livres nos neurônios entéricos, provocada pelo envelhecimento, é favorecida pela 
diminuição significativa de antioxidantes. A utilização do antioxidante, ácido ascórbico, na neutralização dos radicais livres é mais um fator que pode causar redução na concentração de radicais livres em indivíduos. O ácido ascórbico acelera a absorção intestinal dos íons de ferro e sua mobilização, e influencia sua distribuição dentro do organismo. A absorção do ácido ascórbico ocorre no jejuno e no íleo, que são porções distais do intestino delgado, sendo para isto necessária a presença de sódio na luz intestinal. Através da análise quantitativa dos neurônios do jejuno de ratos envelhecidos, tratados com e sem ácido ascórbico, buscou-se evidenciar a preservação destes neurônios. Utilizou-se 10 ratos albinos machos da linhagem Wistar, sacrificados em idade de 428 dias. Os segmentos do jejuno foram submetidos à técnica de coloração de Giemsa. Submetidos à contagem de neurônios em microscópio de luz, no aumento de 40X, em 80 campos. Os resultados obtidos demonstraram que ocorreu um aumento significativo na contagem dos neurônios do jejuno, no grupo de animais envelhecidos com 428 dias tratados com ácido ascórbico, em relação ao grupo controle. O ácido ascórbico é um antioxidadante, e ocorreu provavelmente, um impedimento na formação de radicais livres, e desta forma preservou-se o número de neurônios, atuando, portanto, como neuroprotetor dos neurônios do jejuno, de ratos envelhecidos.

Apoio financeiro: CNPq

\begin{abstract}
ANÁLISIS DE TENDENCIAS DE LOS SOMATOTIPOS DE FUTBOLISTAS DE DIFERENTES GRUPOS ETÁREOS, APLICANDO SOFTWARE READECUACIÓN 2008. Analysis of tendencies of the somatotypes of soccer players of different cohorts, applying a readecuation software 2008. Almagià Flores Atilio A.1; Berlinger Montané Andrés1; Lizana Arce Pablo J.1; Rodríguez Rodríguez Fernando J.1; Barraza Gómez Fernando O.1; J. Ivanovic Marincovic Daniza M.2; Binvignat Gutiérrez Octavio.1-3; Briones Muñoz Pablo A.1; Canedo Astudillo Alvaro I.1; López Montes Enzo J.1; Pinilla Andrade Fidel A1. 1Laboratorio de Antropología Física y Anatomía Humana. Instituto de Biología. Pontificia Universidad Católica de Valparaíso, Chile. 2Universidad de Chile, Instituto de Nutrición y Tecnología de los Alimentos (INTA). 3RS-Brasil.
\end{abstract}

Para la antropometría y estudios de la morfoestructura humana se emplean una infinidad de ecuaciones matemáticas que inicialmente eran resueltas con papel y lápiz, posteriormente fue apoya- do por una calculadora, posteriormente con diversos software. De acuerdo a los requerimientos de nuestras investigaciones es necesario readecuar la forma del cálculo individual del somatotipo de Heath \& Carter. Este nuevo instrumento nos permitirá, confección de somatocartas promédiales, identificar el comportamiento de los componentes de somatotipo en los sujetos estudiados y mostrar gráficamente comportamientos y tendencias de los componente biotipológicos. El $n=144$ jugadores de fútbol profesionales de seis equipos a nivel nacional, $n=12$, everton juvenil 2006; $n=30$, everton juvenil $2007 ; n=17$ PUCV 2007; $n=251^{\circ}$ equipo everton 2007; $n=32$; trasandino 2007; n=28; la serena 2007. La evaluación es realizada por antropometristas validados por ISAK y de acuerdo a los requerimientos éticos y protocolos estandarizados. Se usa instrumental calibrado y validado para este tipo de protocolo. Se toma como base el software de Heath-Carter para el cálculo del somatotipo individual, el software de composición corporal que incluye somatotipo, elaborado por Francis Hollwey (2006). Se modifica la graficación del somatotipo, permite hacer una evaluación en somatocarta individual y grupal. Arroja como resultado una evaluación y clasificación de los tres componentes tanto en forma individual como grupal. Se realiza en planilla Excel, con un costo de cero \$, compatible con Microsoft office, de fácil aplicabilidad y amigable para los usuarios. Conclusiones: Se dispone de un software 2008, que permite el cálculo del somatotipo de Heath\&Carter individual y grupal que permite un análisis de clasificación grupal de gran utilidad cuando se desea mostrar una tendencia de grupos y entrenamiento. Software que permite un seguimiento individual y grupal de los deportistas, en la somatocarta y en la clasificación de proporcionalidad de los tres componentes.

Palabras clave: Software Somatotipo - Composición Corporal - Futbol

Financiado por la Dirección de Investigación. Laboratorio de Antropología Física y Anatomía Humana. Pontificia Universidad Católica de Valparaíso. Chile

\section{ANASTOMOSIS INTERCORONARIAS EN CORAZO-} NES DE AVESTRUZ. (Struthio Camelus). Intercoronary anastomosis in ostrich hearts. (Struthio camelus). Riquelme. J1.; Henríquez, H.2. Henríquez, H.1 1Universidad de La Frontera. Facultad de Medicina. Ciencias Básicas. 2Universidad Santo Tomás. Programa de Magister en Morfologia. UFRO. 
El avestruz pertenece a un grupo de aves denominadas ratites, las cuales son aves terrestres, sus antepasados podían volar, pero se fueron poco a poco adaptándose a usar sus patas como medio principal de locomoción. El estudio del corazón de avestruz ha sido escaso y especialmente en lo relativo a las valvas cardíacas. Bezuidenhout (1984) señala que la valva atrioventricular derecha es una estructura gruesa y triangular que deriva del músculo longitudinal del ventrículo derecho. El material consiste en 50 corazones de avestruz con un peso de $667,75 \pm 137,21 \mathrm{~g}$, cuyas edades están entre 1 año y 1 año y 3 meses, con un peso promedio de $92 \mathrm{~kg}$. Estos fueron lavados con agua corriente y las arterias coronarias inyectadas con Látex Neopreno 650 Dupont, rojo la coronaria derecha, y amarillo la coronaria izquierda, fijados en formalina al $10 \%$ durante 10 días. Se realizó una disección macroscópica y mesoscópica con el fin de efectuar las observaciones. Hubo anastomosis intercoronarias en 45/50 (90\%) de los corazones, donde se observó 1 anastomosis en 22/50 (22\%), 2 anastomosis en $10 / 50(10 \%)$ y 3 anastomosis en $13 / 50$ (26\%). El total de anastomosis fue de $81(100 \%)$; en $39(48,1 \%)$ de los casos fue entre la rama circunfleja y subsinuosa; en $20(24,6 \%)$ de los casos fue entre las ramas del cono derecha e izquierda; en $22(27,3 \%)$ de los casos fue entre las ramas paraconal y subsinuosa. El diámetro de estas anastomosis varió entre 0,44 y $3,40 \mathrm{~mm}$ con una media de $2,42 \pm 1,32 \mathrm{~mm}$. Los resultados son discutidos con otros autores como Martín (1965); Hadziselimovic, et al, (1974); Bezuidenhout (1984); Bull \& Martins (2002) entre otros.

Palabras clave: Arterias coronarias, anastomosis intercoronarias, corazón de avestruz.

\section{ANATOMIA HUMANA: A APRENDIZAGEM ACADÊMICA E SUA IMPORTÂNCIA PROFISSIONAL. Esteves, T.C.1lama, E.A.L.2, 1 Professor de Neuroanatomia - Esamaz, 2 Professor de Anatomia - FAZ,Belém,Pará,Brasil.}

A pesquisa tem como objetivo mensurar o interesse do estudo da disciplina de Anatomia Humana na grade curricular nos cursos da área da saúde, sua importância na formação do futuro profissional da área e as dificuldades encontradas no processo de aprendizagem da disciplina. A pesquisa foi realizada através da aplicação de um questionário comum realizado em duas instituições de ensino superior localizadas na cidade de Belém-PA, no período de abril a maio de 2008 em cursos diferentes da área da saúde na qual a disciplina de Anatomia Humana faz parte da grade curricular. O questionário possuía cinco (5) perguntas de múltipla escolha respondidas de forma aleatória por alunos que já tivessem cursado pelo menos um semestre da disciplina. Participaram da pesquisa 98 alunos de graduação sendo que destes, 98 alunos (100\%) relataram ter interesse no estudo da disciplina no curso de graduação, 97 alunos $(98,98 \%)$ consideram a disciplina muito importante para seu futuro profissional, 53 alunos $(54,08 \%)$ relataram que a maior dificuldade no aprendizado é a nomenclatura das estruturas anatômicas. Quanto ao processo de avaliação utilizado nas provas práticas 79 alunos $(80,61 \%)$ consideram que o mesmo ocorre de forma satisfatória e 67 alunos $(68,36 \%)$ consideram a carga horária da disciplina insuficiente dentro da grade curricular. Conclusão: Os resultados sinalizam que a disciplina de Anatomia Humana desperta grande interesse nos alunos durante a formação acadêmica e que é considerada de fundamental importância na formação do futuro profissional da área da saúde. A nomenclatura das estruturas se encontra como uma das principais dificuldades encontradas no processo de aprendizagem e a carga horária da disciplina é considerada insuficiente para preencher as necessidades dos alunos.

\section{ANATOMICAL BASIS OF TRANSSYLVIAN ACCESS TO MIDDLE CEREBRAL ARTERY. Guedes-Corrêa,} J. F.1, M.D., Phd; Siquara, A. C. M.2 1José Fernando Guedes-Corrêa, Neurosurgery Section, Hospital Universitário Gaffrée \& Guinle; Anatomy Department, Universidade Federal do Estado do Rio de Janeiro (UNIRIO). Escola de Medicina e Cirurgia (EMC). Universidade Federal do Estado do Rio de Janeiro (UNIRIO), Rio de Janeiro, Brazil. 2Ana Caroline Moura Siquara, Graduate in Medicine EMC/UNIRIO, Scholarshiper IC/UNIRIO. Escola de Medicina e Cirurgia (EMC). Universidade Federal do Estado do Rio de Janeiro (UNIRIO), Departamento de Anatomia Humana Rua Frei Caneca, $n^{\circ} 94$ - Disciplina de Anatomia Humana - Centro - 22211040, Rio de Janeiro, RJ - Brazil. Tel. +55(21)87211861 Email: anasiquara@gmail.com

The lateral sulcus is an important referential point in the human brain, as it splits the frontal, parietal and temporal lobes. The middle cerebral artery runs through all its extension, and it's also one of the most common aneurysm localizations. The transsylvian access is very used in neurosurgery because it allows the manipulations of orbital, retroorbital, sellar, chiasmatic, subfrontal and temporal, sphenoid ridge, pre-pontine 
and clival superior areas, cavernous sinus and the most part of anterior circulation and 3rd superior part of basilar artery; the dissection of lateral sulcus and lateral sulcus cistern of the brain is one of the main surgery step of this access. Our objective is to describe the surgical anatomy of the transsylvian access to middle cerebral artery. Key anatomical elements to broach the middle cerebral artery: Lateral sulcus: deep slit that splits the frontal, temporal and parietal lobes, running laterally from the brain basis. Cistern of lateral fossa: subarachnoid cistern used as natural access via. It contents middle cerebral artery and branches, superficial and deep middle cerebral veins (including insular branches and fronto-orbital veins). Its inferomedial limit is on the origin of middle cerebral artery, from the bifurcation of internal carotid artery, where fibers of arachnoid membrane spread out from olfactory trigone until temporal lobe. These thick fibers recover the origin of middle cerebral artery and form a strong adherence between frontal and temporal lobes. In pathological process (for example, cerebral aneurysms) they can become the visualization of middle cerebral artery impossible, what difficult the dissection of the cistern and increases the risk of pial lesion in the operculae. Clots also can be present in its interior. Middle cerebral artery: in its beginning, it's in the lateral sulcus's medial limit, laterally to optic chiasma, inferiorly to anterior perforated substance and posteriorly to olfactory tract division. Then the course is lateral in the interior of lateral sulcus, parallel and some posterior to sphenoid ridge the cistern of lateral sulcus the cerebral artery divides itself, bends postero-superiorly and goes to insular surface. All its parts (M1, M2, M3 and M4) are anatomically related to lateral sulcus. Superficial middle cerebral vein: it can be on temporal or frontal lobes, lateral sulcus, two localizations at the same time or absent; single, double or multiple veins. Deep middle cerebral vein: closely related to posterior and superior walls of lateral sulcus, localized postero-superior to horizontal part of middle cerebral artery. Knowing the localization and relationships between the reference points cited below is important to appropriated exposure of the lesion and less manipulation of intracranial content.

\footnotetext{
ARTERIA CORONARIA ÚNICA EN CORAZONES DE AVESTRUZ. (Struthio camelus). RELATO DE UN CASO. Single coronary artery in heart of the ostrich (Struthio camelus) Relate of a case. Henriquez, J1; Henriquez, H2.; Troncoso, C. 2 1Universidad de La Frontera. Facultad de Medicina. Ciencias Básicas. 2Universidad Santo Tomás. Programa de Magister en Morfologia. UFRO.
}

El avestruz pertenece a un grupo de aves denominadas ratites, las cuales son terrestres, sus antepasados podían volar, pero se fueron poco a poco adaptándose a usar sus miembros pélvicos como medio principal de locomoción. Bezuidenhout (1982, 1984), en sus publicaciones sobre las arterias coronarias del avestruz no ha señalado la ausencia de alguna de estas arterias coronarias. La presencia de una arteria coronaria es considerada una malformación congénita que podría condicionar a un déficit en la perfusión coronaria y ser causa de sintomatología isquémica (Gomez-Aldavari et al., 1998). Fueron analizados 100 corazones de avestruz cuyas edades están entre 1 año y 1 año y 3 meses, con un peso promedio de $92 \mathrm{~kg}$. Estos fueron lavados con agua corriente y masajeados previamente. Para una mejor visualización de las arterias coronarias fueron previamente cateterizadas a través de sus ostios e inyectadas con Látex Neopreno 650 Dupont, de color rojo para la arteria coronaria derecha, y de color amarillo para la arteria coronaria izquierda, y fijados en formalina al $10 \%$ durante 10 días. Fue observada la ausencia de la arteria coronaria derecha, la cual nace como una pequeña rama desde la arteria coronaria izquierda, que se dirige, entre la aorta y la arteria pulmonar al surco coronario reemplazando a la arteria coronaria derecha. La arteria coronaria izquierda posee un diámetro de $6.05 \mathrm{~mm}$ mientras que la rama derecha tiene un diámetro de $2,5 \mathrm{~mm}$ y un recorrido de $90.4 \mathrm{~mm}$ alcanzando el margen derecho del corazón. Los resultados son discutidos con otros autores como Bezuidenhout (1982, 1984); De la Torre et al. (1998); Gomez-Aldavari (1998); Barriales-Villa (2006) entre otros.

Palabras clave: Arterias coronarias, Arteria coronaria única, corazón de avestruz.

\section{BLIND TEST OF MANDIBULAR MORPHOLOGY WITH SEX INDICATOR IN SUBADULT MANDIBLES.}

Test Ciego de la morfología mandibular como indicador de sexo en mandíbulas de subadultos. Suazo G.I.C 1, 2; Zavando M.D.A1; Smith R.L2. 1Departamento de Anatomía Normal, Universidad de Talca. 2Departamento de Morfología y Genética. Universidad Federal de Sao Paulo, Brasil.

Loth \& Henneberg (2001) indicaron que era posible la determinación del sexo con un alto nivel de exactitud $(81 \%)$ en mandíbulas de niños mediante la observación de la forma del cuerpo mandibular. El propósito de este estudio fue evaluar la consistencia del método propuesto, para ello se utilizaron 33 mandíbu- 
las de niños brasileros de entre 0 y 1 año de edad, de sexo conocido, pertenecientes a la colección de cráneos de la Universidad federal de Sao Paulo (UNIFESP). Se realizó un test ciego en dos sesiones por un solo observador, en base al parámetro descrito por Loth \& Henneberg. Los resultados obtenidos muestran un entre un 57.5 y $60.5 \%$ de exactitud, siendo el test más sensible para la determinación del sexo masculino $(70 \%)$, que para el sexo femenino $(38-46 \%)$. Los resultados expuestos son inferiores a los reportados por Loth \& Henneberg y justifican la necesidad de evaluar los métodos de diagnóstico del sexo en subadultos en poblaciones específicas.

Palabras clave: Dimorfismo sexual; Determinación del sexo; Subadultos; Mandíbula.

CARACTERÍSTICAS ANATÓMICAS DE LA VALVA ATRIOVENTRICULAR DERECHA EN CORAZONES DE AVESTRUZ (Struthio camelus). Anatomical characteristic of the right atrioventricular valve in ostrich hearts. (Struthio camelus). Carvallo, E.1.; Figueroa, M2; Henríquez, H1. Carvallo, E 1; Henríquez, J. 3 1 Universidad Santo Tomás. Programa de Magister en Morfologia. UFRO. 2Universidad del Bio-Bio. Programa de Magister en Morfologia. UFRO. 3Universidad de La Frontera. Facultad de Medicina. Ciencias Básicas.

El avestruz pertenece a un grupo de aves denominadas ratites, las cuales son aves terrestres, sus antepasados podían volar, pero se fueron poco a poco adaptándose a usar sus patas como medio principal de locomoción. El estudio del corazón de avestruz ha sido escaso y especialmente en lo relativo a las valvas cardíacas. El material consiste en 30 corazones de avestruz con un peso de $667,75 \pm 137,21 \mathrm{~g}$, cuyas edades están entre 1 año y 1 año y 3 meses, con un peso promedio de $92 \mathrm{~kg}$. Se realizó una incisión con tijera desde el anillo atrioventricular derecho, en dirección al ápice del corazón siguiendo el margen de éste, para dejar visible la valva atrioventricular derecha, los corazones fueron fijados en formalina al 10\% durante 10 días. Se realizó una disección macroscópica y mesoscópica con el fin de efectuar las observaciones. Hubo presencia de la valva atrioventricular derecha en todos los casos, presentándose como sólo una hoja o cúspide, opuesta a la pared septal, en el plano espiral del miocardio, cuyas fibras musculares se aíslan del anillo del miocardio ventricular por un tejido conjuntivo que cubre el anillo fibroso. En contraste con las características de la estructura fibrosa de la válvu- la del tricúspide mamífero. Su longitud fue de 46,02 \pm $8,24 \mathrm{~mm}$, con rangos entre 37,51 y $63,00 \mathrm{~mm}$; su anchura fue de $28,41 \pm 5,45 \mathrm{~mm}$ con rangos entre 18,22 y 38,95 y su espesor de $4,79 \pm 1,27 \mathrm{~mm}$ con rangos entre 3,14 y $8,36 \mathrm{~mm}$. Los resultados son discutidos con otros autores como Wade \& Nelly (1949); Lieberman \& Paes De Carvalho (1965); Bezuidenhout (1984); Szabó et al. (1986); Lu et al. (1993).

Palabras clave: Valva atrioventricular derecha; Ventrículo derecho, corazón de avestruz.

\section{CARACTERIZACIÓN DEL SOMATOTIPO Y LA COM- POSICIÓN CORPORAL DE LOS ALUMNOS INGRE- SADOS EL AÑO 2007 A LA CARRERA DE EDUCA- CIÓN FÍSICA Y SU COMPARACIÓN CON SU DES- EMPEÑO FÍSICO EN LAS EVALUACIONES DIAGNÓSTICAS DE CONDICIÓN FÍSICA.}

Somatotype a characterization and body composition of students enrolled in the physical education program year 2007 and its comparison with their physical performance in the diagnostic evaluations of physical training conditions. Almagià Flores Atilio A1.; Lizana Arce Pablo1; Rodríguez Rodríguez Fernando J1.; Barraza Gómez Fernando O.; J1 . Ivanovic Marincovic Daniza M2. Binvignat Gutiérrez Octavio1-3 ; Navarrete Bravo Hariscel Andrea; Paredes Cuéllar Nathalie Michele; Troncoso Villa Amanda Natalia. 1Laboratorio de Antropología Física y Anatomía Humana. Instituto de Biología. Pontificia Universidad Católica de Valparaíso, Chile. 2Universidad de Chile, Instituto de Nutrición y Tecnología de los Alimentos (INTA). 3RSBrasil.

No existen antecedentes de la morfoestructura inicial de los estudiantes de Educación Física (PUCV). Podemos suponer que presentarían un somatotipo ecto- mesomórfico y una composición corporal con predominio de la masa muscular y bajo porcentaje de masa grasa por lo que deberían obtener un mejor desempeño físico en las evaluaciones diagnósticas. Pretendemos establecer relaciones, entre las morfoestructuras de los alumnos ingresados el año 2007 a la carrera de Educación Física de la PUCV y su desempeño físico en las pruebas diagnósticas de condición física. Sujetos y Métodos: Estudiantes que ingresan a primer año de la carrera de educación Física, $n=50, n=18$ damas y $n=32$ varones, a los cuales debidamente informados y contando con su consentimiento, se les aplica el protocolo de evaluación de Heath-Carter para determinar el somatotipo y para la composición corporal y fraccionamiento corporal en 
cinco componentes, se emplea la metodología de $\mathrm{D}$. Keer (1988). Para la evaluación de la condición física, se efectúa una evaluación diagnóstica empleando una serie de baterías estandarizadas: Resistencia: $2.400 \mathrm{~m}$; Resistencia muscular miembro superior: barras; Fuerza explosiva: detente vertica; Fuerza abdominal: Abdominales, Hombro y Velocidad: 50m. Se obtiene una relación directa entre los valores de composición corporal y rendimiento físico. Los varones resultan ser ectomesomorfos, las damas son mesoendomorfos. En varones $n=26$ tienen $<26 \%$ de masa grasa $n=30$, varones presentan $>45 \%$ de masa muscular. En las damas tenemos $n=6$ tienen $>30 \%$ masa grasa y un $n=6$ tienen $>45 \%$ masa muscular. Se detecta que a mayor porcentaje de masa grasa menor será la resistencia y a mayor \% de masa muscular mayor será la resistencia en las pruebas de rendimiento físico. De acuerdo a la distribución de los componentes morfológicos, se podrá determinar el rendimiento del sujeto. Al conocer el somatotipo y la composición corporal, se podrá orientar el entrenamiento para lograr un rendimiento eficiente. Mediante un buen entrenamiento podemos llegar a favorecer el somatotipo y la composición corporal del sujeto, beneficiando su rendimiento físico.

Palabras clave: Somatotipo - Composición Corporal - Desempeño Físico

Financiado por la Dirección de Investigación. Laboratorio de Antropología Física y Anatomía Humana. Pontificia Universidad Católica de Valparaíso. Chile

COMPARACIÓN DE DOS TÉCNICAS DE REGISTRO
DE DATOS PARA ESTUDIOS DE MORFOMETRÍA
LINEAL Y GEOMÉTRICA A TRAVÉS DEL ESTIMA-
DOR TAMAÑO DE CENTROIDE. TWO registermethods comparison for linear and geometric morphometrics studies using centroid size value. María Viviana Toro Ibacache, Germán Manríquez Soto. Facultad de Medicina, Universidad de Chile

El uso de técnicas de morfometría lineal y geométrica ha sido de gran relevancia en anatomía, donde han ampliado el conocimiento de las formas en estudio. Herramientas como la computación han ido ganando terreno en la investigación morfométrica. En anatomía y antropología física es común el uso de la fotografía digital como método de registro y aún se pueden encontrar técnicas de registro directas, que son más engorrosas. Ambas se asumen equivalentes, ¿pero lo son realmente?. Se estudió esta equivalencia utilizando el tamaño de centroide, valor que de- pende de la posición de hitos anatómicos, y es sensible a su registro. Se utilizaron 18 radiografías A-P de cráneos de poblaciones arqueológicas del norte de Chile, por representar una estructura compleja y a la vez de fácil registro. Se seleccionaron tres hitos medianos (vertex, crista galli y paladar) y 8 hitos bilaterales (mastoide, parietal, vertex-parietal, arco cigomático, ala mayor y menor del esfenoides, incisura nasal, proceso cigomático). Se utilizaron además 35 triángulos dibujados en papel milimetrado. Se registraron radiografías y triángulos, con el brazo digitalizador MicroScribe 3DX (Inmersion Co., Palo Alto, Ca.) y su programa computacional InScribe; y con la máquina fotográfica Fujifilm FinePix 6900Zoom y el programa tpsDig (v. 1.40@ J. Rohlf, Ecology \& Evolution, SUNY at Stony Brook). Para obtener el tamaño de centroide con ambos métodos de registro se utilizó el programa tpsRelative Warps (v. 1.42 (c) J. Rohlf, Ecology \& Evolution, SUNY at Stony Brook). La prueba estadística utilizada fue la prueba t de Student con un nivel de significancia de 0.05 , y se utilizó la prueba de correlación $r$ de Pearson. Ambas técnicas resultaron equivalentes en el análisis de triángulos $(p=0.8269, r=0.9789)$, pero no en el de radiografías $(p<0.05, r=-0.05)$. Conclusiones: Las técnicas son equivalentes sólo para análisis de formas simples, por lo que no pueden compararse resultados en estudios de formas complejas, como el cráneo, cuyas muestras hayan sido registradas con las dos maneras.

Palabras clave: Morfometría Lineal y Geométrica, Técnicas de Registro.

Financiado por: Proyecto FONDECYT 1050279

\section{COMPOSICION CORPORAL Y SOMATOTIPOS DE UNA MUESTRA DE RUGBY FEMENINO DE LA QUINTA REGIÓN. Body composition and somatotypes} of a rugby team female sample of the fifth region. Almagià Flores Atilio A1.; Lizana Arce Pablo J1.; Rodriguez Rodríguez Fernando J1.; Barraza Gómez Fernando O1.; J. Ivanovic Marincovic Daniza M. 2; Binvignat Gutiérrez Octavio1-3; Brito Jeldres Felipe1; Ibacache Orrego, Jonathan1; López Quezada, Soledad1; Zamora Valencia, Carlos1. 1Laboratorio de Antropología Física y Anatomía Humana. Instituto de Biología. Pontificia Universidad Católica de Valparaíso, Chile. 1Universidad de Chile, Instituto de Nutrición y Tecnología de los Alimentos (INTA). 1RS-Brasil.

El rugby femenino, es un deporte que ha incrementado fuertemente a nivel mundial. Se obser- 
va un creciente número de niños y adultos interesados en su práctica; en los numerosos campeonatos de esta disciplina existentes hoy en día en nuestro país, ya sea a nivel escolar, regional y nacional. Considerando el crecimiento progresivo que ha tenido este deporte los últimos años, la participación femenina, creemos que es importante realizar un estudio de somatotipo y composición corporal en jugadoras de Rugby femenino de la $\mathrm{V}$ región, con la finalidad de contar con antecedentes fiables de la morfoestructura femenina de dicho deporte. Dos equipos femeninos: Sporting Rugby Club, Viñas del Mar; $n=9$, y Equipo Universitario UTFSM, Valparaíso, $\mathrm{n}=12$., bajo su consentimiento informado. Se evaluó bajo el protocolo de la International Society for the Avancement in Kineanthropometric (ISAK)., por evaluadores con licencia nivel II de ISAK. Se utilizan las formulas de composición corporal de D. Kerr (1988) y para el método antropométrico del Somatotipo de HeathCarter (1990) Se usó un kit antropométrico Rosscraft SRL validado por la ISAK. La tendencia del somatotipo en ambos equipos es mesomorfo-endomorfo. La masa muscular predomina por sobre las otras masas; la masa adiposa es casi tres veces superior al resto (residual, ósea, piel). La masa muscular predomina por sobre las otras masas, pero menor en relación a las mujeres de la universidad técnica Federico Santa María,. Comparando los dos equipos de rugby femenino se pudo apreciar que de las veinte y un jugadoras siete son mesomorfo-endomorfo, seis son endo-mesomorfo, cuatro son meso-endomorfo, dos son central, una es mesomorfo-balanceado y una es ectomorfo-balanceado. Existe una tendencia al mesomorfo-endomorfo y al endo-mesomorfo ya que representan más de la mitad de las jugadoras medidas. La relación existente entre masa muscular y masa adiposa es inversamente proporcional. Sobre la distribución adiposa se puede concluir que a pesar de que ambos equipos presentan una adiposidad no muy diferente no existe la tendencia que se pensaba en un comienzo, por lo que se puede decir que no necesariamente equipos que practiquen el mismo deporte presenten una tendencia de distribución adiposa en sus distintas regiones. Al analizar las somatocartas de ambos equipos se pudo observar que la tendencia es mesomorfo-endomorfo.

Palabras clave: Somatotipo - Composicion Corporal - Rugby - Femenino

Financiado por la Dirección Investigación. Laboratorio de Antropología Física y Anatomía Humana. Pontificia Universidad Católica de Valparaíso. Chile
COMUNICACIÓN PREVIA SOBRE LAS VARIEDADES DE PRESENTACION DEL TRONCO SIMPATICO TORÁCICO. Cunha, Mariana.G.A.T.; Bergottini, C.H.; Moreno, D.E.; Manader Piovano, N.G. Director: Bergottini, C. H. Cátedra I de Anatomía Humana Normal e Imagenología. Prof. Dr. Civetta, J. D. Facultad de Medicina. Universidad Nacional del Nordeste. Corrientes. Argentina.

E-mail cesar_bergottini@yahoo.com.ar

La actividad del tronco simpático torácico (TST) está vinculada, principalmente, con el control de la actividad visceral. Toda esta actividad puede verse afectada por patologías propias de sus estructuras, como así también de los sistemas con los que se interrelaciona estrechamente, generando síndromes complejos y difícil interpretación. El objetivo del trabajo es describir las variedades de la presentación a nivel de la parte simpática del sistema autónomo torácico, ya que es necesario el conocimiento básico de la distribución y variabilidad de estas estructuras nerviosas a fin de interpretar clínica y racionalmente las anomalías y fundamentar las prácticas clínico-quirúrgicas. El diseño es de tipo descriptivo. Se utilizaron piezas cadavéricas adultas, de ambos sexos, formolizadas al $10 \%$. Se emplearon técnicas e instrumentos de disección y biometría convencionales, con magnificación óptica de 5X y 10X. Los datos fueron tabulados aplicándose métodos estadísticos que fueron graficados e interpretados. Se documentó fotográficamente en forma panorámica y focalizada. El material empírico obtenido demuestra variedades del tronco y del número de ganglios: Variedad 1 con 12 ganglios en 6 casos (20\%); Variedad 2 con 11 ganglios en 9 casos (30\%); Variedad 3 con 10 ganglios en 14 casos (46,6\%); Variedad 4 con 9 ganglios en 1 caso $(3,3 \%)$. Con respecto a las variedades del nervio esplácnico mayor los datos empíricos se asemejan a la literatura clásica. La variabilidad usual ocurre en el $23 \%$ de los casos. En relación al nervio esplácnico menor esta presente en el $100 \%$ y su variabilidad corresponde a las descripciones clásicas. Lo cual se hace extensivo a las variedades de los nervios esplácnicos inferior y accesorio. Se han corroborado empíricamente las variedades del TST existentes en nuestro medio en la actualidad. El conocimiento de tales variaciones del TST pueden ser de ayuda para los cirujanos, pudiendo ser evitada alguna denervación incompleta o prevenir algún daño involuntario durante la simpatectomía torácica.

Palabras clave: Sistema Nervioso Autónomo.Tronco Simpático Torácico. 
CÓNDILO MANDIBULAR BÍFIDO: REPORTE DE CASOS. Bifid mandibular condyle: Cases reports. Fuentes, R.; Silva, H. \& Morales, P. Deptos. de Odontología Integral y Ciencias Básicas. Universidad de La Frontera. Temuco, Chile.

El condílo bifido es una rara anomalía. La mayoría de los casos han sido identificados en forma incidental en los exámenes radiográficos, principalmente en ortopantomografía y en resonancia nuclear magnética, siendo esta condición usualmente asintomática, sin embargo en algunos casos se asocia con anquilosis de la articulación temporomandibular. Se reporta que la ocurrencia de los cóndilos bífidos no demuestra diferencia de edad y genero, y la edad de aparición se informa en un rango de 3 a 67 años, con un promedio de 35 años. Evaluamos tres individuos por medio de una radiografía panorámica. Se encontró tres pacientes los cuales tenían esta rara condición siendo unilaterales y bilaterales. El condílo bífido es una rara anomalía del desarrollo y poco discutida. (Gundlach, K; Fuhrmann, A.; Beckmann-Van der Ven, 1987). La mayoría de los casos han sido identificados en forma incidental en los exámenes radiográficos, principalmente en ortopantomografía y en resonancia nuclear magnética, siendo esta condición usualmente asintomática, sin embargo en algunos casos se asocia con anquilosis de la articulación temporomandibular. (Shriki, et al., 2005; De Moraes Ramos, et al., 2006). Es necesario prestar atención a esta rara condición del punto de vista clínico ya que podría ser parte del síndrome mandibular-facial-digital-pezones. ATM.-

Palabras clave: Mandíbula, Condílo bifido,

CONSIDERACIONES ANATÓMICAS SOBRE EL NERVIO ALVEOLAR INFERIOR. Cabás Geat, Angeles E.;Ormaechea, María S.; Bergottini, C.H., Baez, C.A. Director: Dr. Bergottini C. H. Cátedra I de Anatomía Humana Normal e Imagenología. Prof. J. D. Civetta. Sargento Cabral 2001. CP 3400 . Facultad de Medicina. UNNE. Corrientes. Argentina.

Email: cabasgeat@hotmail.com

El nervio mandibular posee dos tronco terminales, anterior y posterior. El tronco terminal posterior se divide en cuatro ramas siendo la más voluminosa el nervio alveolar inferior. Este se dirige hacia abajo por delante de la arteria alveolar inferior entre la fascia interpterigoidea y el músculo pterigoideo medial, el músculo pterigoideo lateral y la mandibula por fuera de él. Penetra en el canal mandibular acompañado de la arteria alveolar inferior. Da cuatro ramos colaterales y finaliza en dos ramas terminales, el mentoniano que sale por el agujero del mismo nombre, y el nervio incisivo que se dirige hacia delante y da ramos al canino, a los incisivos y a la encía. Al analizar la literatura mundial encontramos escasas publicaciones respecto al nervio alveolar inferior (NAI) y su trayectoria en el conducto mandibular. La mayor parte de lo publicado esta en relación a los reparos óseos más confiables para ubicar al NAI con el fin de realizar diferentes procedimientos estomatológicos. Nuestro objetivo es describir las características o variables que presenta el $\mathrm{NAl}$ en su trayecto mandibular, teniendo en cuenta su importancia clínico-quirúrgica en los traumatismos maxilos-faciales. El diseño utilizado corresponde al tipo descriptivo. Se utilizaron 30 piezas cadavéricas adultas de ambos sexos conservadas en solución acuosa de formaldehído al 10\%, se realizó biometría y disecó con técnicas, instrumentos convencionales. Se realizó registros fotográficos panorámicos y focalizados. A los datos obtenidos se aplicaron métodos estadísticos que se tabularon y graficaron. El material empírico obtenido muestra: Variedad I o clásica (Rouvière): con dos ramas terminales, el nervio mentoniano que atraviesa el agujero del mismo nombre y el nervio incisivo también llamado plexo dentario inferior que se dirige al canino, los incisivos y a la encía correspondiente. Esta disposición fue observada con alta frecuencia en la muestra, correspondiéndose a un $75 \%$ de lo casos, representadas en 23 piezas cadavéricas. Variedad II, el nervio alveolar inferior se divide desde su entrada en el conducto mandibular en dos ramas terminales y en este caso no existe plexo dentario (Olivier). Dicha disposición se obtuvo con una frecuencia relativamente escasa, alcanzando el $25 \%$ de la muestra, con un total de 7 piezas que la representan la observación. Los objetivos se han cumplido ya que se ha producido información básica sobre el trayecto del NAI en nuestro medio, para ser utilizado en las practicas clínicos quirúrgicas. Confirmándose la escasa variabilidad que presenta el nervio alveolar inferior.

Palabras clave: Neuroanatomía. Nervio alveolar inferior. Variedades.

\section{CONTAMINACIÓN POR COLEÓPTEROS EN PIE-} ZAS ANATÓMICAS - PULMONES INSUFLADOS. Almagià Flores Atilio A.1; Lizana Arce Pablo J. 1; Binvignat Gutiérrez Octavio1-2. 1Laboratorio de Antropología Física y Anatomía Humana. Instituto de Biología. Pontificia Universidad Católica de Valparaíso, Chile. 2RS-Brasil. 
Para insuflar pulmones se comienza con el lavado del sistema respiratorio con agua corriente para hacer una fijación rápida, después de la inyección de aire para verificar si todo el sistema está hermético. La fijación es lograda a través de formol entre $20-30 \%$ por 20 minutos, a continuación se dispone una solución que contiene: solvente, (Thinner o Aguarras) de $500 \mathrm{ml}$.; Éter sulfúrico 200ml.; Peróxido de Hidrógeno 200ml.; Alcohol $96^{\circ}$ $\mathrm{Gl}$. $100 \mathrm{ml}$. La solución es inyectada en las vías aéreas, haciendo que toda la arquitectura pulmonar se mantenga deshidratada, eliminando el tejido adiposo, evitando así la degradación de la estructura, conjuntamente se conecta la pieza a un compresor de aire expandiendo los pulmones. La deshidratación y secado es interna, se usa una estufa para la parte externa. El método requiere un tiempo mínimo de 3 a 4 días con inyección continúa de aire. Luego las piezas son barnizadas con laca brillante teniendo en su composición polímero alquídico modificado, aceites vegetales, hidrocarburos aromáticos (excepto benceno), hidrocarburos alifáticos, agentes tenso-activos, secantes órgano-metálicos. Las piezas anatómicas sufrieron contaminación por coléopteros que atacan principalmente el parénquima pulmonar. La descontaminación se realizó depositando los pulmones insuflados dentro de un recipiente y luego aplicando a través de un tubo $\mathrm{JIMO} \otimes$ Gas Humeante aplicando así un contacto más prolongado e intenso a las piezas. Fue dejado en el recipiente cerrado con el material adentro durante 72 horas, después de la apertura del recipiente y la inspección de los pulmones fue verificada la inexistencia de insectos. Se presentan algunos efectos laterales, como superficies ásperas e impregnadas de una ceniza blanquecina en las caras pulmonares de difícil limpieza. Las estructuras fueron aseadas y barnizadas nuevamente con barniz marítimo brillante mezclado con una solución de naftalina al $40 \%$.

Palabras clave: Técnicas anatómicas - pulmones insuflados - contaminación

Financiado por Laboratorio de Antropología Física y Anatomía Humana. Pontificia Universidad Católica de Valparaíso, Chile.

CORRELACIÓN ANATOMO-CLÍNICA DEL APARATO ESTILOIDEO POR TC HELICOIDAL CON RECONSTRUCCIÓN 3D EN VARIANTE DEL SINDROME DE EAGLE. Zago, D.E.; Aguirre, E.A.; Buján, Ma- ría L.; Rolnik, María C. Director: Zarza, A. Cátedra I de Anatomía Humana Normal e Imagenología. Prof. Dr. Civetta, J. D. Facultad de Medicina. U.N.N.E. Corrientes. República Argentina. E-mail: master_zeus_8@hotmail.com.

El aparato estiloideo está constituido por el asta menor del hueso hioides, proceso estiloideo del hueso temporal (PE) y ligamento estilohioideo (LEH); estos dos últimos atraviesan el espacio maxilofaríngeo, teniendo estrecha relación con el contenido vásculonervioso del espacio retroestiloideo. La elongación del PE y/o calcificación del LEH producen el Síndrome de Eagle (SDE) que en su variante estilocarotídea al comprimir la arteria carótida interna e irritar los ramos del par IX destinados al corpúsculo carotídeo desencadenan sincope, dolor y vértigo. La TC Helicoidal es el método de elección para su diagnóstico. El objetivo de este trabajo radica en una descripción de las relaciones del aparato estiloideo con las estructuras adyacentes evidenciables por TC 3D, correlacionándola con bibliografía de anatomía y la signosintomatología del síndrome. En paciente de 74 años con SDE variante estilocarotídea, se empleó un tomógrafo volumétrico (marca General Electric) de 64 detectores con reconstrucciones 3D. Parámetros técnicos escogidos: 120 kV y 600 mAs con inyección de $30 \mathrm{ml}$ de solución fisiológica y 50 $\mathrm{ml}$ de contraste a $7 \mathrm{ml} / \mathrm{seg}$ a través de bomba de doble cabezal. Software de "volume rendering" para posprocesamiento de datos. Los cortes tomográficos fueron coronales y sagitales oblicuos. En los cortes tomográficos se evidenció alargamiento del proceso estiloideo bilateral que alcanzó los 55 $\mathrm{mm}$ en el lado izquierdo y $41 \mathrm{~mm}$ en el derecho (valores normales entre 25 y $30 \mathrm{~mm}$ ), asociado a calcificación del ligamento estilohioideo bilateral. Asimismo se pudo constatar claramente una íntima relación del ligamento estilohioideo con los vasos y nervios del espacio retroestiloideo, en particular con la arteria carótida interna y el nervio glosofaríngeo. Los resultados obtenidos reflejan la relevancia del conocimiento de la anatomía del espacio maxilofaríngeo para dilucidar la clínica que denotan las afecciones del aparato estiloideo en el síndrome de Eagle, como así también, el papel protagónico de la TC 3D para la evaluación de las estructuras anatómicas de dicha región.

Palabras clave: síndrome de Eagle, variedad estilocarotidea, ligamento estilohioideo, tomografía volumétrica. 
CORRELACION ANATORADIOLOGICA DE LAS RAMAS PARIETALES EXTRAPELVICAS DE LAARTERIA ILIACA INTERNA. Correlation anatoradiological of the parietal extrapelvic braches of internal iliac artery. Zago, D.E.; Sisul Larrosa, L.E.; Vega Mendoza, M.J.; Moreschi, F. Director: Harvey, W. Cátedra I de Anatomía Humana Normal e Imagenología. Prof. Dr. Civetta, J.D. Facultad de Medicina. U.N.N.E. Corrientes. República Argentina.

La arteria ilíaca interna es rama terminal de la arteria ilíaca común, en su trayecto da origen a ramas viscerales y parietales intrapélvicas y extrapélvicas dentro de estas últimas encontramos a las glútea superior, glútea inferior, pudenda interna y obturatriz. Los orígenes de estas arterias no siempre son los mismos presentando de esta manera variaciones en cuanto a su origen. El objetivo de este estudio fue determinar la frecuencia de dichas variaciones mediante disección cadavérica y estudios tomográficos volumétricos para su aplicación clínica quirúrgica. El diseño del trabajo es de tipo descriptivo. Para el presente estudio se utilizaron 22 cadáveres conservados en formol al 10\%, de tallas, edades y sexos diferentes, provistos por la cátedra. Se utilizó la técnica de disección clásica, cuyo objetivo es demostrar el origen y trayecto de las ramas parietales extrapélvicas en las piezas cadavéricas. Además se ocupó un Tomógrafo Volumétrico Multislice (General Electric VCT High Speed), utilizando inyección de sustancia de contraste yodada (Yodo Hidrosoluble) por vía endovenosa con bomba, ocupando para el estudio imágenes de la categoría Volume Rendering, en 42 voluntarios, seleccionados aleatoriamente. Se tabularon los datos obteniéndose inferencias estadísticas. Los resultados obtenidos permiten establecer las siguientes variaciones: arteria glútea superior: en el 100\% (64 casos) se origina del tronco posterior de la arteria ilíaca interna. arteria pudenda interna: en el $59,37 \%$ (38 casos) se origina de un tronco común con la arteria glútea Inferior; en un $23,44 \%$ ( 15 casos) nace independientemente de la arteria ilíaca interna y en el $17,19 \%$ (11 casos) se origina de la rama anterior de la arteria llíaca Interna. Arteria glútea inferior: en el $73,44 \%$ (47 casos) nace de la división anterior de la arteria ilíaca interna; en el $21,87 \%$ (14 casos) se origina de la división posterior de dicha arteria y en el 4,69\% (3 casos) proviene de la arteria ilíaca interna. Arteria obturatriz: en el 37, 5\% (24 casos) se origina de la división anterior de la arteria ilíaca interna; en el 17,19\% (11 casos) proviene del arteria iliaca común; en el 15,62\% (10 casos) nace de la arteria epigástrica inferior; en el 14,07\% (9 casos) parte de la división posterior de la arteria ilíaca inter- na; en el 9,37\% (6 casos) se origina de la arteria ilíaca interna antes de su división; mientras que en el 6,25\% (4 casos) nace junto con la arteria rectal media. Se logró material científico relevante para las prácticas médicas, propias del accionar clínico-quirúrgico, fundamentado por estudios por imágenes. De las ramas extrapélvicas, la arteria glútea superior es la única que se origina de la rama posterior de la arteria Ilíaca Interna, mientras que las arterias glútea inferior, pudenda interna y obturatriz se originan del tronco anterior, siendo esta última arteria la que presenta mayores variaciones en cuanto a su origen. Es importante resaltar que durante la búsqueda, no se detectado variedades no descriptas con anterioridad.

Palabras clave: Angiología - llíaca Interna - Variedades - Tomografía Volumétrica.

\section{DISECCIÓN Y DESCRIPCION DE LAS VARIEDADES DE PRESENTACIÓN DEL MÚSCULO GASTROC-} NEMIO. Dissection and description of varietys to presentation of the gastrocnemius muscle. Arce, Yanina V.; Almiron, Yesica P.; Almada Ruíz Díaz, Montserrat; Encinas Nuñez, C. G. Director: Dr. Bergottini, C.H. Cátedra I de Anatomía Normal e Imagenología. Prof.: Dr. Civetta, J. D. Facultad de Medicina UNNE. Corrientes Argentina. Sargento Cabral 2001. CP: 3400. Tel: (054)-(03783)-423478

E-mail: yaninavanesa_arce@hotmail.com

El músculo gastrocnemio está constituido por dos cabezas, una cabeza y una lateral. La cabeza medial se origina en una depresión situada sobre el cóndilo medial del fémur, inferior y posterior al tubérculo del aductor magno y en el tubérculo supracondileo medial. La cabeza lateral en una fosita situada posterior al epicóndilo lateral del fémur y en el tubérculo supracondileo lateral. Distalmente se inserta en la tuberosidad del calcáneo uniéndose a los tendones del músculo sóleo formando el tendón calcáneo. El siguiente trabajo tiene como objetivo determinar las características y formas de presentación del músculo gastrocnemio, a fin de producir un conocimiento más detallado que fundamente las prácticas clínico-quirúrgicas y el posterior uso didáctico pedagógico de las piezas. El diseño es de tipo descriptivo. Se disecaron 40 piezas cadavéricas formalizadas al $10 \%$ de individuos adultos de ambos sexos. Los instrumentos utilizados fueron los clásicos elementos de biometría y disección, magnificación óptica de $2 x$ y $5 x$. Se documentó las presentaciones a través de registros fotográficos en forma focalizada y panorámica. Los datos 
fueron tabulados y analizados estadísticamente. La variedad clásica, descripta por Rouvière y Testut, fueron halladas en 22 piezas (52.5\%) de las piezas estudiadas. Los resultados permitieron determinar que, de las quince variedades de presentación descriptas por Macallister, en cuanto a su origen, se hallaron: -Tres piezas $(7.5 \%)$ en la que una tercera cabeza puede surgir desde la línea áspera del cóndilo medial, por encima de la cabeza medial del músculo gastrocnemio. En cuanto a su inserción, hallamos: Nueve piezas $(22.5 \%)$ en la que el tendón del músculo gastrocnemio se une al cuerpo carnoso del músculo sóleo en el tercio medio. -Cinco piezas (12.5\%) en la que el tercio inferior de la cabeza lateral del músculo gastrocnemio se une con los dos tercio inferiores del músculo sóleo; -Dos piezas (5\%) en la que el tendón del músculo gastrocnemio se une en el tercio inferior del tendón del músculo sóleo. Concluimos que los datos empíricos corroboran las descripciones clásicas y que nuestros objetivos fueron alcanzados ya que logramos hallar las variedades descriptas, que fundamentan las prácticas clínicos -quirúrgicas.

Palabras clave: Miología. Músculo gastrocnemio. Variedades

\section{DISECCIÓN Y DESCRIPCIÓN DE LAS VARIEDADES DE PRESENTACION DEL MÚSCULO EXTENSOR ULNAR DEL CARPO. Prado, Marisa S. V; Amarilla,} J.C.; Toledo, Libertad, D.B.; Sorba, Viviana M. L. Director: Dr. Bergottini, C.H. Cátedra I de Anatomía Humana Normal e Imagenología. Prof.: Dr. Civetta, J. D. Facultad de Medicina. UNNE. Dirección: Sargento Cabral 2001-Corrientes-Capital. Argentina CP: 3400 E-mail:msvp_86@hotmail.com

El músculo extensor ulnar del carpo, es un músculo con origen en el epicóndilo lateral y discurre por la cara posterior del antebrazo en el plano superficial, terminando en la parte medial de la extremidad proximal del quinto metacarpiano. El objetivo del trabajo consiste en la revisión y descripción de la unidad de análisis, y sus variables más importantes; para lograr una buena correlación clínico-quirúrgica; siendo nuestra región predominantemente agrícola-ganadera, en la cual, los accidentes del miembro superior son muy frecuentes. El diseño del trabajo es de tipo descriptivo, empleándose 36 piezas cadavéricas fijadas con formol al $10 \%$ de individuos adultos de ambos sexos. Los instrumentos utilizados fueron los elementos clásicos de disección y magnificación óptica de $2 X$ y $5 X$. Se documentó las presentaciones a través de registros fotográficos en forma focalizada y panorámica. Los datos fueron tabulados y analizados estadísticamente. El análisis del material empírico muestra: que de las 36 piezas cadavéricas $(100 \%) 30$ piezas (83.33\%) presentaron: La variedad I -clásica (Rouvière y Testut): el tendón se inserta en la parte medial de la extremidad proximal del quinto metacarpiano. Según Macallister, solo se hallaron: Variedad II: 4 piezas (11.11\%): Expansión fibrosa se inserta en la cápsula de la articulación metacarpofalángica del quinto dedo. Variedad III: 1 pieza (2.66\%): Expansión fibrosa se inserta en la extremidad distal del quinto metacarpiano. Variedad IV: 1 pieza (2.66\%): Expansión fibrosa a la cara medial del cuerpo del quinto metacarpiano. Concluimos que los datos empíricos corroboran las descripciones clásicas y que se ha producido material de información básica para fundamentar las prácticas clínico-quirúrgicas y material didáctico para uso docente para la cátedra.

\section{DISECCIÓN Y DESCRIPCIÓN DE LAS VARIEDADES} DE PRESENTACION DEL MÚSCULO OPONENTE DEL PULGAR. Prado, Marisa S.V; Amarilla, J.C.; Toledo, Libertad D.B.; Sorba,Viviana M. L. Director: Dr. Bergottini, C.H. Cátedra I de Anatomía Humana Normal e Imagenología. Prof: Dr. Civetta, J. D. Facultad de Medicina- Universidad Nacional del Nordeste. Sargento Cabral 2001- Corrientes. Argentina. E- mail :msvp_86@hotmail.com .

El músculooponente del pulgar es un músculo, que tras originarse por sus fibras superficiales en la parte ántero-lateral del retináculo flexor y por sus fibras profundas en la cara anterior y parte lateral de la cresta del trapecio, se dirige lateralmente para insertarse en la vertiente lateral del primer metacarpiano, en toda su extensión. Con el presente trabajo pretendemos analizar, verificar las variedades de presentación y características morfológicas de dicho músculo con la finalidad de aportar información a las prácticas clínico-quirúrgicas. Siendo nuestra región agrícola ganadera las lesiones musculares del miembro superior son muy frecuentes. El diseño del trabajo es de tipo descriptivo, se utilizaron 35 piezas cadavéricas adultas de ambos sexos, fijadas con formol al $10 \%$. Se emplearon técnicas de disección y biometría con instrumental convencional, magnificación óptica de 2 $X$ y $5 X$ y registro fotográfico panorámico y focalizado. Se realizó la tabulación y análisis estadístico de los datos. El análisis del material empírico muestra: Variedad I ó clásica (Testut-Latarjet): en 29 piezas 
(82.85\%), tal como fue descripta la unidad de análisis anteriormente. Variedad II: Expansión fibrosa al fascículo superficial del músculo flexor corto prolongando así sus inserciones hasta el hueso sesamoideo lateral (Testut-Latarjet), en 6 piezas (17.14\%). Los resultados afirman que los objetivos fueron alcanzados obteniéndose conocimientos importantes para ser tenidos en cuenta en las prácticas clínico quirúrgicas.

\section{DISECCIÓN Y DESCRIPCIÓN DE LAS VARIEDADES DE PRESENTACIÓN DEL MÚSCULO FIBULAR TER-} CERO. Machado, R.J.; González, M.A.; Casco, N.S.; Machado, María S. Director: Dr. Bergottini, C H. Cátedra I de Anatomía Humana Normal e Imagenología: Prof. Civetta, J D. Facultad de Medicina. UNNE. Corrientes, Argentina. C.P. 3400. Sargento Cabral 2001. TEL.: 054 (03783) 423478

El presente trabajo tiene como objetivo determinar las formas de presentación del músculo fibular tercero, a fin de producir un conocimiento más detallado de sus características y frecuencia que fundamente las prácticas clínicas quirúrgicas de nuestro medio. Poco conocida es la relevancia clínica de este músculo. Podría estar asociado al rompimiento del tendón del músculo fibular corto, posible subluxación del tendón fibular y a una prominente eminencia retrotroclear. Por lo tanto consideramos que reside aquí la importancia clínico-quirúrgica de este músculo, viéndose afectado con mucha frecuencia en los pacientes con traumatismo de miembros inferiores como producto de accidentes de tránsito y también en lo que respecta a las lesiones producidas en los deportes de contacto donde se vea afectada principalmente la articulación del tobillo. Este trabajo es de tipo descriptivo, donde se utilizaron 33 piezas cadavéricas de adultos de ambos sexos formalizados al $10 \%$ con las técnicas e instrumentos convencionales de disección y microdisección. Se utilizó magnificación óptica 2x y 5x. Se registró gráficamente con fotografías panorámicas y focalizadas, con motivo de estudiar las inserciones y variantes de cada una de ellas. Se realizó la biometría del origen e inserción, como así también de la longitud de la porción tendinosa y carnosa de este músculo. El diseño utilizado es de tipo descriptivo transversal, debido a que revisa las características fundamentales que permiten poner de manifiesto la estructura delmúsculo fibular tercero, además considera asociar las variables y relacionarlas, pero sin establecer si unas son determinantes o causas de las otras por lo que no necesariamente debe partir de una hipótesis. Los datos empíricos permitieron determinar que de las 33 piezas (100\%): Variedad I: 21 piezas $(63,63 \%)$ corresponden a la variación clásica (según Rouvière y Testut), cuya inserción distal es en la base del $5^{\circ}$ metatarsiano. De las 13 variedades de presentación descriptas por Macalister se pudo hallar la Variedad II: 10 piezas $(30,30 \%)$ en la cual el músculo se encuentra ausente; Variedad III: 1 pieza $(3,03 \%)$ en donde el músculo puede presentar doble tendón. También se pudo hallar la Variedad IV: 1 pieza $(3,03 \%)$ en la cual el tendón del músculo fibular tercero se hallaba perforado por el tendón del músculo fibular largo; variedad aún no descripta por la bibliografía clásica. Concluimos que los objetivos propuestos fueron alcanzados debido a que los datos empíricos corroboran que las observaciones realizadas en nuestro medio durante la investigación coinciden en su mayoría con las descripciones clásicas (según Rouvière y Testut); además se ha producido material de información básica para el uso didáctico y pedagógico de las piezas en nuestra cátedra y un conocimiento mas detallado para fundamentar las prácticas clínico-quirúrgicas de nuestra región.

Palabras clave: Miología. Músculo Peroneus Tertius. Variedades. Revisión.

\section{DISECCIÓN Y REVISIÓN DE LAS VARIEDADES DEL MÚSCULO EXTENSOR LARGO DE LOS DEDOS.} Krywinski, F.M.; Vallejos D.C.A.; Sánchez, D.C.E.; Fernández, Sandra D. Director: Dr. Bergottini, C.H. Cátedra I de Anatomía Humana Normal e Imagenología. Prof. Dr. Civetta, J.D. Facultad de Medicina. U.N.N.E. Sargento Cabral 2001 Tel.: (054)(03783)-423478. Corrientes Capital. Argentina. Código postal: 3400 E-mail:f_kry@hotmail.com

El músculo extensor largo de los dedos es un músculo, cuyo tendón se divide en cuatro expansiones terminales, que se dirigen a los 4 últimos dedos del pie. El objetivo del trabajo consiste en la revisión y descripción de la unidad de análisis y de sus variables más importantes, para que en futuros abordajes quirúrgicos y reconstructivos se tengan en cuenta, debido a la frecuencia de lesiones que se producen en el miembro inferior. El diseño del trabajo es de tipo descriptivo, empleándose 40 piezas cadavéricas de ambos sexos, fijadas con formol al $10 \%$. Se recurrieron a técnicas de disección y biometría con instrumental convencional, magnificación óptica de $2 \mathrm{X}$ y $5 \mathrm{X}$ y registro fotográfico panorámico y focalizado. Los resultados fueron tabulados y analizados estadísticamente. El análisis del material empírico mostró: Variedad clási- 
ca: en 19 piezas (47,5\%). Variedad II: El tendón se divide antes de pasar por debajo del retináculo de los músculos extensores: en 14 piezas (35\%). Variedad III: Un vientre muscular para cada uno de los tendones: en 9 piezas $(22,5 \%)$. Variedad IV: El tendón del $5^{\circ}$ dedo emite expansiones hacia el músculo fibular tercero: en 4 pieza (10\%). Variedad V: Un desliz del tendón del $3^{\circ}$ dedo hacia el músculo extensor corto de los dedos: en 2 piezas (5\%). Variedad VI: Tendón doble para el $5^{\circ}$ dedo: en 1 pieza $(2,5 \%)$. Variedad VII: El tendón del $5^{\circ}$ dedo emite un desliz para el músculo fibular tercero; otro para la cara dorsal del cuerpo del $5^{\circ}$ metatarsiano; y otro más delgado para la cápsula de la $5^{\circ}$ articulación metatarso-falángica: en 1 pieza (2,5\%). Variedad VIII: Un desliz del tendón del $5^{\circ}$ dedo para la cápsula de la articulación metatarso-falángica: en 1 pieza (2,5\%). Variedad IX: El tendón único se divide en uno lateral y otro medial. El tendón medial forma el tendón para el $2^{\circ}$ dedo, para el $3^{\circ}$ dedo y una raíz medial para el tendón del $4^{\circ}$ dedo. El tendón da una raíz lateral para el tendón del $4^{\circ}$ dedo y forma el tendón del $5^{\circ}$ dedo: en 1 pieza $(2,5 \%)$. Variedad X: El tendón del $5^{\circ}$ dedo se divide en tres: en 1 pieza $(2,5 \%)$. Variedad XI: El tendón del $4^{\circ}$ se bifurca en su parte proximal, uniéndose a él mismo en su parte distal: en 1 pieza $(2,5 \%)$. Variedad XII: El tendón del $2^{\circ}$ dedo emite un desliz para la cápsula de la articulación metatarso-falángica: en 1 pieza (2,5\%). Los resultados obtenidos reflejan una amplia variabilidad del músculo con respecto al origen y disposición de sus diversos tendones. También cabe destacar que en una misma pieza se han hallado múltiples variedades del mismo músculo. Debido a la frecuencia obtenida de las variedades analizadas, las mismas deben tenerse presentes, tanto así en las prácticas clínico-quirúrgicas como para lograr una óptima reconstrucción y rehabilitación tras una lesión del miembro inferior, alcanzando así la funcionalidad normal del mismo y obteniendo como resultado mínimas secuelas.

DISECCIÓN Y REVISIÓN DE LAS VARIEDADES DEL MÚSCULO FIBULAR TERCERO. Rindel, Sabrina D; Cardoso, Ileana M; Espinoza, Victoria A; Vallejos, D.C.A. Director: Dr. Bergottini C. H. Cátedra I de Anatomía Humana Normal e Imagenología. Prof. Dr. Civetta, J.D. Facultad de Medicina. U.N.N.E. Sargento Cabral 2001 Corrientes, Argentina. E-mai vallejosdiego81@hotmail.com

El músculo fibular tercero, se origina por medio de fibras musculares del tercio inferior de la fíbula, de la membrana interósea y del tabique intermuscular que lo separa de los músculos fibulares largo y corto. El cuerpo muscular se dirige inferior y anteriormente, atraviesa el retináculo inferior de los músculos extensores, luego se dirige ánterolateral e inferiormente, insertándose en la cara dorsal de la base del quinto metatarsiano. El objetivo del trabajo consiste en la revisión y descripción anatómica de la unidad de análisis y de sus variables más importantes, debido a que son muy frecuentes las lesiones y fracturas del miembro inferior, sobre todo por accidentes de tránsito y de trabajo en nuestra región del nordeste. El diseño del trabajo es de tipo descriptivo, empleándose 40 piezas cadavéricas adultas de ambos sexos, fijadas con formol al $10 \%$. Se recurrieron a técnicas de disección y biometría con instrumental convencional, magnificación óptica de $2 \mathrm{X}$ y $5 \mathrm{X}$ y registro fotográfico panorámico y focalizado. Los resultados fueron tabulados y analizados estadísticamente. El análisis del material empírico muestra: Variedad clásica:(Rouvière-Testut): Se inserta en la cara dorsal de la base del quinto metatarsiano. (80\%). Variedad II:(Macalister) La inserción distal, en la base del cuarto metatarsiano, emitiendo dos expansiones tendinosas, uno al cuerpo del cuarto y otra al quinto metatarsiano. (5\%). Variedad III: (Macalister). Tendón doble: una expansión tendinosa hacia la base del cuarto metatarsiano, y otra hacia la base del quinto metatarsiano. (2,5\%). Variedad IV: Tendón doble: una expansión hacia la base, y otra hacia el cuerpo del quinto metatarsiano. $(2,5 \%)$. Variedad V: Expansión tendinosa hacia la cara lateral de la base del quinto metatarsiano. (2,5\%). Variedad VI: Ausencia del músculo fibular tercero. (7,5\%). Los resultados obtenidos reflejan una amplia variabilidad del músculo en nuestro medio, que deberán tenerse presente en futuros abordajes quirúrgicos para evitar su lesión. Además concluimos que en la mayoría de las piezas disecadas, la unidad de análisis se encuentra presente, oponiéndose a lo descripto por la bibliografía de referencia.

DISECCIÓN Y REVISIÓN DE LAS VARIEDADES DEL MÚSCULO TIBIAL POSTERIOR. Krywinski, F.M.; Matzner Perfumo, Mariana; Rapaccioli, Mara D.; Ramírez, N.E. Director: Dr. Bergottini, C.H. Cátedra I de Anatomía Humana Normal e Imagenología. Prof. Dr. Civetta, J.D. Facultad de Medicina. U.N.N.E. Sargento Cabral 2001 Tel.: (054)-(03783)-423478. Corrientes, Argentina. Código postal: 3400 E-mail: f_kry@hotmail.com

El músculo tibial posterior es un músculo que tras originarse por medio de fibras carnosas en los dos 
tercios superiores de la cara posterior de la tibia, en la parte lateral del labio inferior de la línea del sóleo de la tibia, en los dos tercios superiores de la cara medial de la fíbula, en la membrana interósea de la pierna y en los tabiques fibroso que lo separan de los músculos flexores largos, desciende en sentido inferior y medial, terminando en un tendón que contornea el borde posterior del maléolo medial, reflejándose inferior y anteriormente y va a insertarse en la tuberosidad del hueso navicular, por expansiones radiadas hacia la planta del pie, en los tres huesos cuneiformes, el cuboides, y en la base de los metatarsianos $2^{\circ}, 3^{\circ} \mathrm{y}$ $4^{\circ}$. Nos planteamos como objetivo, la revisión y descripción anatómica de la unidad de análisis y de sus variables más importantes. El diseño del trabajo es de tipo descriptivo, se utilizaron 40 piezas cadavéricas adultas de ambos sexos, fijadas con formol al $10 \%$. Se emplearon técnicas de disección y biometría con instrumental convencional, magnificación óptica de $2 X$ y $5 X$ y registro fotográfico panorámico y focalizado. Se realizó la tabulación y análisis estadístico de los datos. El análisis del material empírico mostró: Variedad Clásica: en 29 piezas (72,5\%). Variedad II: Expansión fibrosa hacia el tendón del Peroneo largo: en 4 piezas (10\%). Variedad III: Expansión fibrosa al Flexor corto del dedo gordo: en 3 piezas $(7,5 \%)$. Variedad IV: No emite expansión fibrosa al $4^{\circ}$ metatarsiano: en 2 piezas (5\%). Variedad V: Expansión fibrosa hacia el $5^{\circ}$ metatarsiano: en 2 pieza $(5 \%)$. Variedad VI: No emite expansión fibrosa al cuboides: en 1 pieza (2,5\%). Los datos obtenidos corroboran las descripciones clásicas, aunque no por eso se debería desestimar las variedades del músculo Tibial posterior, ya que en su conjunto se presentan con una frecuencia importante. Se ha producido material de información básica para fundamentar las prácticas clínico-quirúrgicas.

\section{EFFECT OF THE SEVERE MALNUTRITION TO DATE OF DEATH ON THE MORPHOLOGIC TRAITS OF THE SEXUAL DIMORPHISM IN HUMAN SKULL.}

Efecto de la desnutrición severa a la data de muerte sobre parámetros morfológicos de dimorfismo sexual en cráneos humanos. Suazo G.I.C 1, 2; Zavando M.D.A1; Cantín L.M.G1; Smith R.L2. 1Departamento de Anatomía Normal, Universidad de Talca 2Departamento de Morfología y Genética. Universidad Federal de São Paulo, Brasil.

Uno de los propósitos más importantes del protocolo antropológico de estudios osamentas humanas es la determinación del sexo. Algunos cráneos pue- den ser clasificados erróneamente debido a condiciones sistémicas presentes durante la vida de individuos que afectan las fuerzas musculares que actúan sobre el hueso, como es el caso de la desnutrición severa. El propósito de este estudio es determinar el efecto de la desnutrición severa sobre parámetros morfológicos clásicamente estudiados en el análisis visual del cráneo. Se utilizaron 163 cráneos humanos con sexo, edad y causa de muerte conocida, pertenecientes a la colección de la UNIFESP. Se realizó la inspección visual del cráneo y el diagnóstico de sexo en base a: tamaño y arquitectura general del cráneo, aspecto del hueso cigomático, tamaño y rugosidades del proceso mastoides, rugosidades del hueso occipital y aspecto general de la mandíbula. Posteriormente los cráneos fueron clasificados en dos grupos de acuerdo a si presentaron desnutrición severa descrita en su causa de muerte $(n=60)$ o presentaban otra causa de muerte $(n=103)$. Los resultados de la inspección se compararon con la del registro para determinar la exactitud en el diagnóstico y la sensibilidad del método para hombres y mujeres en los dos grupos analizados. En el grupo con desnutrición el mejor indicador resultó el aspecto del hueso cigomático, con un $86.6 \%$ de exactitud. En el otro grupo la mayor exactitud se encontró en el tamaño de la mastoides (87.3\%). En ambos grupos los mayores valores de sensibilidad fueron para hombres (83.3-95.3\%). La sensibilidad para mujeres presentó menores valores en el grupo sin desnutrición (69.2-76.9\%) que en el grupo con desnutrición (72.4-89.65\%), estas diferencias resultaron estadísticamente significativas $(p<0.05)$.

Palabras clave: Dimorfismo sexual; Determinación del sexo; Desnutrición severa.

ENSEÑANZA, INTERACCIÓN Y EVALUACIÓN CON ALUMNOS VIRTUALES EN UN CURSO DE TÉCNICAS ANATÓMICAS. Almagià Flores Atilio A.1; Lizana Arce Pablo J. 1; Binvignat Gutiérrez Octavio12. 1 Laboratorio de Antropología Física y Anatomía Humana. Instituto de Biología. Pontificia Universidad Católica de Valparaíso, Chile. 2 RS-Brasil.

La educación está pasando por una renovación de sus espacios, resignificación de contenidos y de valores, teniendo como punto de partida los acelerados procesos sociales. Actualmente, con la disponibilidad del Internet y de la World Wide Web (WWW), nuevas técnicas han sido desarrolladas para interactuar a distancia para la formación de nuevos 
profesionales de la enseñanza superior. En materias concretas como la Anatomía Humana donde las estructuras son fácilmente observables además de ser registradas por distintas técnicas de imágenes, se posibilita la visualización interactiva y tridimensional de alta definición de datos científicos. En este caso, usuarios en sitios remotos pueden visualizar simultáneamente un conjunto de datos, cuyo análisis es controlada por ellos (Coleman 1996, Elvins 1996.). Sujetos y métodos: La disciplina de técnicas anatómicas para el curso de magíster $n=20$ se planifica en una etapa presencial utilizando diversas didácticas (clases interactivo-expositivas, análisis de artículos científicos, actividades prácticas) y un segundo período de seis meses dinamizado y facilitado por educación de distancia (EAD). En esta última etapa se ocupó la WEB como plataforma para el desarrollo de EAD con "PONTOTEC" y TELEDUC, correos electrónicos y una serie de software para procesamiento de imágenes y su envío. Resultados: Tuvimos un $100 \%$ de interactividad entre los participantes, así como una continua dinámica entre los participantes del proceso. Se recibieron más de 1.013 visitas a la plataforma virtual. Los e-mails cuentan más 625 sin contar respuestas de los mismos. A través del proceso de EAD las técnicas anatómicas trabajadas lograron los objetivos esperados. La EAD es un método importante que debe ser incorporado a las prácticas de educación superior, inclusive en disciplinas que necesitan como base fundamental la práctica.

Palabras clave: Educación a distancia - Enseñanza - Aprendizaje - técnica anatómicas

Financiado por el Laboratorio de Antropología Física y Anatomía Humana. Pontificia Universidad Católica de Valparaíso. Chile

ENSEÑANZA Y APRENDIZAJE DE LA MORFOLOGÍA DE SISTEMA NERVIOSO EN ESTUDIANTES DE UN PROGRAMA DE TALENTOS ACADÉMICOS. Lizana, P.1.; Almagià, A. 1; Binvignat, O.G.3 Henríquez, R.1; Arenas, A.2; Gómez, M.2; Conejeros, M.2 . 1Laboratorio de Antropología Física y Anatomía Humana, Instituto de Biología, Pontificia Universidad Católica de Valparaíso; 2Pontificia Universidad Católica de Valparaíso, Programa Beta, 3RS- Brasil.

El talento académico se presenta en un $6 \%$ a $10 \%$ de la población (Saste, S, 2008) y se caracteriza por la presencia de un alto potencial intelectual el cual se traduce en la posesión de habilidades cognitivas, sociales, entre otras, que se manifiestan en distintas áreas del conocimiento. Sujetos y métodos: El siguiente trabajo muestra la aplicación de un método de enseñanza activo-participativo de la morfología del sistema nervioso para estudiantes con talento académico de los dos últimos años de la enseñanza secundaria $(n=20)$ y edades promedio de 16,5 st 0,51 , que forman parte de un programa de enriquecimiento curricular (Programa BETA). Este método integra las clases interactivas, donde se presentan y discuten los temas, se realizan pasos prácticos que incluyen disecciones, confección de modelos tridimensionales, seminarios de investigación y técnicas anatómicas, además de un refuerzo continuo a través del Aula Virtual (Lizana, P et al 2007). Todos los estudiantes forman parte del Curso "Neurociencias: desde las neuronas al cómo aprendemos", realizado durante el primer semestre 2008. Resultados: A través de las metodologías utilizadas, se han maximizando las posibilidades de aprendizaje de los estudiantes. Esto, combinado con el talento académico que presentan y su avidez de conocimiento, permite que cada estudiante avance a su propio ritmo y además descubra a través de la experiencia directa ("hands-on activities" Escalada, 2001) la morfología de nuestro sistema nervioso. Discusiones: Este estudio pretende mostrar variantes del aprendizaje neuroanatómico para su posterior evaluación, tanto de los contenidos aprendidos, como de las habilidades (procesos de comunicación, recepción y apropiación de los contenidos) por parte de los estudiantes con talento académico participantes y que son atribuibles a las metodologías activas de enseñanza utilizadas.

Palabras clave: Neuroanatomía, talentos, enseñanza, aprendizaje, metodologías activo-participativas.

Financiado por el Programa Beta y Laboratorio de Antropología Física y Anatomía Humana. PUCVChile.

ESTUDIO ANATÓMICO DE LAS REGIONES UTILIZADAS PARA LA APLICACIÓN DE INYECCIONES INTRAMUSCULARES. Anatomic study of regions use for the application of intramuscular injections. Expucci, M. V.; Puyol Iris A; Ford María L; Salas Gabriela B. Director: Dr. Bergottini, C. H. Cátedra I Anatomía Humana Normal e Imagenología. Prof. Titular: Dr. Civetta, J. D. Facultad de Medicina UNNE Sargento Cabral 2001 Corrientes Capital (3400) Republica Argentina. Teléfono: 054- (03783) 423478. E-mail: mvexpucci@hotmail.com 
Las inyecciones son un importante recurso en la práctica médica, así como, un método eficaz para la prevención de enfermedades. Existen diferentes vías para inyectar un medicamento como son: la vía subcutánea, la intravenosa, la intradérmica, o la intramuscular. Esta última es de inmensa utilidad como medio clínico, pero destaca aún más su elección como método preventivo, por ser el de elección para la inmunización artificial activa (vacunación). En este trabajo describiremos las zonas de mayor uso en Argentina para esta práctica, siendo estas la Región Deltoidea (RD), la Región Glútea (RG) y el Músculo Vasto Lateral (MVL); justificando, anatómicamente, la razón de su empleo. Finalmente, propondremos cual de ellas es la más conveniente para la practica médica.

Palabras clave: Regiones anatómicas; Aplicación de inyecciones; Intramusculares; Lesiones. UNNE.

Financiado por la Facultad de Medicina de la

EVALUACIONES PRÁCTICAS OBJETIVADAS EN ANATOMÍA. PREGUNTAS EN MODELOS, PREPARACIONES ANATÓMICAS Y CADÁVERES.

Objective structured practical evaluations in anatomy: Questions on models, preparations and cadaver. Oscar Inzunza, Alex Vargas. Departamento de Anatomía, Escuela de Medicina, Pontificia Universidad Católica de Chile.

En la mayoría de los cursos de anatomía de nuestros país los temidos exámenes prácticos se realizan ahora en el formato de pruebas prácticas objetivadas; actividades no menos temidas pero que si ofrecen una similitud de condiciones a todos los examinados. En nuestro caso y atendida la escasez de material cadavérico, una parte de las estaciones de evaluación ocupan preparaciones anatómicas parafinadas o plastinadas y modelos anatómicos de serie que existen en el mercado; material que por sus características no siempre reflejan, en forma fidedigna, la realidad anatómica. En este estudio se compara el rendimiento de los alumnos de nuestros cursos de anatomía en a) disecciones cadavéricas b) preparaciones anatómicas plastinadas; $y, c)$ distintos tipos de modelos anatómicos fabricados especialmente para la docencia en anatomía. Los resultados obtenidos muestran distinto grado de dificultad según el elemento sobre el cual se realiza la evaluación. Así, las peguntas sobre modelos son respondidas con mayor facilidad ( $?=3,219$; escala de 0 a 4 puntos) que aquellas realizadas sobre preparaciones $(?=3,193)$ o cadáveres $(?=2,537)$. Además, hemos detectado que algunos modelos ofrecen mayor dificultad que otros -sobre una misma región anatómica- en el reconocimiento de estructuras anatómicasvasculares. La utilización de modelos y preparaciones anatómicas si bien ayudan en la docencia y las instancias evaluativas de los cursos de anatomía, representan una versión sesgada de la realidad anatómica; hecho que debe ponderarse al momento de definir los objetivos y la intencionalidad de los cursos de anatomía.

Palabras clave: Docencia-Evaluación-ModelosPreparaciones-Cadáveres.

IMPACTO DE FACTORES GENÉTICOS Y AMBIENTALES EN EL ÍNDICE DE MASA CORPORAL (IMC) DE MELLIZOS CHILENOS MONOZIGÓTICOS (MM) Y DIZIGÓTICOS (MD) SEGÚN SEXO. Genetic and environmental factors on body mass index (BMI) in chilean monozygotic (MZ) and dizygotic (DZ) twins of both sexes. Daniza Ivanovic1,2, Elena Llop3, Jorge Alvear1, Hernán Pérez1, Nora Díaz1, Bárbara Leyton1, Atilio Almagià4, Cristián Larraín5, Yilda Herrera1, Joel Alvarez1,2, Elizabeth Hazbún1, Yasna Orellana1 1 Universidad de Chile, Instituto de Nutrición y Tecnología de los Alimentos (INTA); 2 Universidad de Loma Linda, Escuela de Salud Pública, California, USA-Universidad Adventista de Chile; 3 Universidad de Chile, Facultad de Medicina, Instituto de Ciencias Biomédicas, Programa de Genética Humana; 4 Pontificia Universidad Católica de Valparaíso, Instituto de Biología; 5 Clínica Alemana de Santiago, Servicio de Resonancia Magnética e Imágenes.

En las últimas décadas, la transición demográfica y epidemiológica ha tenido lugar en Chile, representada por un considerable aumento de las enfermedades crónicas no transmisibles relacionadas con la dieta, especialmente, de la obesidad. El objetivo general de este estudio fue cuantificar el impacto relativo de factores genéticos y ambientales (compartidos y no compartidos), en la determinación del índice de masa corporal (IMC), en alumnos MM y MD de sexo masculino y femenino. Material y método: Del Registro de Mellizos (REMEUCHI), se seleccionó una muestra representativa, estratificada y proporcional de 112 parejas de mellizos (promedio de edad 18 años), 66 parejas correspondían a MM, 29 de sexo masculino (MMM) y 37 de sexo femenino (MMF)) y 46 parejas a MD, 20 de sexo masculino (MDM) y 26 de sexo feme- 
nino (MDF), que egresaron de educación media el año 2004. El IMC se comparó con las tablas de Garrow. El peso de los factores genéticos $(A)$, el de los factores ambientales compartidos (A) y no compartidos (E) se determinó por el modelo estadístico $\mathrm{Mx}$, para estudios en mellizos. El modelo AE fue el que mejor contribuyó a explicar el IMC. Al respecto, en la muestra total, el $86.4 \%$ del IMC sería atribuible a A y el $13.6 \%$ a E. En el sexo masculino, estos porcentajes fueron para $A$ de $88.8 \%$ y para $\mathrm{E}$ de $11.2 \%$, no siendo bueno el modelo de ajuste. En el sexo femenino, A contribuye a explicar el $83.3 \%$ y E el $16.7 \%$, siendo adecuado el modelo de ajuste. Conclusión: EI IMC es altamente heredado, siendo la heredabilidad mayor en el sexo masculino, en comparación con el sexo femenino y el impacto de los factores ambientales es insignificante en ambos sexos. Herencia

Palabras clave: Indice Masa Corporal, Mellizos,

Financiado por Universidad de Chile, Departamento de Investigación (DI), Proyecto S SOC 04/19-2

INERVACIÓN DE LOS MÚSCULOS INTRÍNSECOS DEL DEDO MÍNIMO DE LA MANO HUMANA.

Innervation of the digiti minimi muscles in the human hand. ${ }^{*}$ Pacheco, J.P. \& ** Olave, E. * Posgraduando Magíster en Ciencias, mención Morfología, U. de La Frontera. ${ }^{* *}$ Facultad de Medicina, Universidad de La Frontera, Temuco, Chile

El conocimiento detallado de la inervación de las estructuras de la mano permite la restauración de sus funciones frente a lesiones a las que se encuentra frecuentemente sometida. El presente estudio tiene por objetivo observar la distribución del ramo profundo del nervio ulnar en los músculos intrínsecos del dedo mínimo, determinando el origen de cada ramo y su punto motor en individuos chilenos. Se disecaron 12 manos de cadáveres de individuos chilenos pertenecientes a la unidad de Anatomía de la Universidad de la Frontera,Chile, en las cuales se realizó disección de la región palmar, exponiendo los músculos hipotenares y el ramo profundo del nervio ulnar (RPNU), siguiendo los ramos musculares, determinando si el origen era independiente o de tronco común y localizando su punto motor en el vientre muscular. En 4 casos (33,3\%) el ramo profundo del nervio ulnar originó un tronco común para los músculos abductor del dedo mínimo (ADM) y flexor corto del dedo mínimo (FCDM) y un ramo independiente para el músculo oponente del dedo mínimo (ODM) En 3 (25\%) el RPNU originó un tronco común para los músculos FCDM y ODM y un ramo independiente para el ADM. En $2(16,7 \%)$ el RPNU originó ramos independientes para cada músculo. En $1(8,3 \%)$, el ADM recibió 2 ramos, uno independiente y otro de un tronco común con el FCDM, recibiendo el ODM dos ramos independientes. En 1(8,3\%) el ADM recibió dos nervios, uno independiente y otro de un ramo común con el FCDM y ODM. En el caso restante $(8,3 \%)$ se observó ausencia del FCDM, donde el RPNU emitió ramos independientes para el ADM Y ODM. En todos los casos el punto motor de cada uno de los músculos se observó en su tercio proximal, a excepción de los dos casos en que el ADM recibió un segundo ramo, el cual ingresó en el tercio medio del músculo. La longitud promedio del ADM fue de $63,7 \mathrm{~mm}$, la del FCDM de $55,6 \mathrm{~mm}$ y la del ODM de $43,5 \mathrm{~mm}$. El estudio de la inervación de estos músculos y sus puntos motores complementará el conocimiento de las estructuras de la mano.

Palabras clave. Anatomía; Mano; Inervación; Nervio ulnar; Músculos hipotenares.

Proyecto DIDUFRO 120631, Universidad de La Frontera, Chile

INNOVACIÓN EN IMAGENOLOGÍA EN PASOS PRÁCTICOS DE ANATOMÍA NORMAL. Innovation in imagenology in practical sessions of Anatomy. Julio Cárdenas V(1), Sandra Arriagada(1), Miguel Soto(1), Mario Bravo(2) Andrea Godoy(3). Facultad de Medicina Universidad de Chile

Por más de 60 años el estudio de las imágenes en los pasos prácticos de Anatomía se ha efectuado mostrando placas de radiografías para luego incorporar ecotomografía, tomografías computadas y resonancias magnéticas no siempre de la mejor calidad. Existiendo además una dificultad evidente en manejar ordenadamente los archivos imagenológicos para distintos cursos. Por ello en vista del avance tecnológico en la práctica clínica hemos decidido: 1.- Modernizar la infraestructura del estudio de imágenes en los pasos prácticos. 2.- Mejorar la base de datos de imágenes médicas. 3.- Crear e incorporar software de uso docente de apoyo a la enseñanza de la anatomía de imágenes, así como también mejorar el estudio de preparados anatómicos de difícil visualización. 4.- Desarrollar software de autoaprendizaje en los alumnos. Se dotaron a los 2 pabellones de disección de 2 pantallas planas de 32 pulgadas cada uno marca SONY 
Bravia con sus respectivos computadores cargados con el sistema operativo Linux, utilizando una selección de imágenes normales del Servicio de Imagenología del Hospital Clínico de la Universidad de Chile, obtenidas de equipos de Radiología SIEMENS, diversos modelos, Scanner SIEMENS Somatron Sensation de 64 canales, con software syngo CT 2006 A-W, Resonador SIEMENS Magnetron Symphony Maestro Class, con software Numaris/4 syngo MR 2004 A. Se realizan y ejecutan softwares previa capacitación a los docentes utilizando los programas Flash y Power Point. Posteriormente se sube un programa de autoaprendizaje en Intranet con acceso para los alumnos. Se evalúa la aceptación de este sistema efectuando una encuesta a los docentes, indagándose la facilidad de uso, calidad de las imágenes y mejora en almacenamiento e incorporación de nuevos estilos de aprendizaje comparándolo con el sistema tradicional. Se evalúa el impacto en los alumnos a través de una encuesta de uso del software en la intranet. Evidente fue la rápida aceptación de este nuevo sistema, tanto para los docentes cómo para los alumnos, mejorando no sólo la calidad de las imágenes, sino también el almacenamiento de ellas, creando nuevos software para la docencia, con directa relación entre la anatomía de cortes e imágenes.

Palabras clave: Docencia, Imagenología

ICBM, Facultad de Medicina Universidad de Chile. Innovación docente, imágenes médicas

MESOSCOPIA, HISTOLOGÍA Y ESTEREOLOGIA COMPARATIVA ENTRE EL BAZO DEL CUYE (Cavia porcellus) Y LA RATA (Rattus novergicus) Sprague Dawley. 1Furrianca, Cristina \& 2Del Sol, Mariano. 1Universidad de Magallanes, 2Universidad de La Frontera, Temuco, Chile.

El bazo es el órgano linfático periférico más grande del organismo con un importante rol en la protección y defensa del organismo. Localizado en el hipocondrio izquierdo, está compuesto por pulpas rojas y blancas y una zona marginal. El objetivo del estudio fue describir el bazo de dos especies: cuye (Cavia porcellus) y rata (Rattus novergicus) analizando sus características anatómicas, histológicas y estereológicas, para así obtener patrones de normalidad cuali-cuantitativos, los que servirán de base para futuros estudios morfofuncionales. Se emplearon 15 ejemplares de cuye (Cavia porcellus) y rata (Rattus novergicus) Sprague Dawley de aproximadamente 5 a 6 meses de edad, clínicamente sanos y mantenidos en cautiverio. De estos, 5 animales fueron disecados observándose las relaciones in situ del órgano. Luego fue extraído el bazo para su estudio anatómico. Para el estudio histológico 5 bazos fueron fijados en formalina tamponada y luego trozos de ellos fueron procesados, obteniéndose cortes de $3 \mu \mathrm{m}$ de espesor, los cuales fueron teñidos con $\mathrm{H}-\mathrm{E}$, Arteta, van Gieson, Tricrómico de Masson, Ramón \& Cajal y Gomori. Para la estereología se usó el método del orientador, se ocuparon 5 bazos, de cada uno de ellos se obtuvieron 5 trozos, y de estos 5 láminas, observándose 5 campos de cada una. Para el recuento se utilizó el sistema test M42. Tanto el bazo del cuye como de la rata se localiza en el hipocondrio izquierdo, unido por ligamentos peritoneales al estómago y páncreas. Presenta dos caras y dos márgenes. Histológicamente, el bazo en ambos animales está compuesto por pulpa roja, pulpa blanca y una zona marginal. El bazo del cuye posee $65,14 \%$ de pulpa roja, $21,96 \%$ de pulpa blanca y $12,67 \%$ de zona marginal. La rata presenta un $53,9 \%$ de pulpa roja, $25,75 \%$ de pulpa blanca y $15,87 \%$ de zona marginal. Existiendo diferencias significativas entre ambos roedores. Con esta investigación se espera haber sentado las bases de los aspectos morfológicos normales para el bazo del cuye (Cavia porcellus) y rata (Rattus novergicus), indispensable para continuar con futuros estudios morfofuncionales y experimentales.

Palabras clave: Morfología; Cuye; Rata; Bazo

MORFOESTRUCTURA: COMPOSICIÓN CORPO-
RAL, SOMATOTIPOS Y PROPORCIONALIDAD EN
JUGADORES DE VOLEIBOL PROFESIONAL Y SE-
LECCIÓN JUVENIL DE CHILE. Almagià Flores Atilio A.1; Lizana Arce Pablo J. 1; Rodríguez Rodríguez Fernando J. 1; Barraza Gómez Fernando O. 1; J. Ivanovic Marincovic Daniza M. 2; Binvignat Gutiérrez Octavio1-3; Benavente, Hernández, Ignacio M. 1; Estay, Abrigo, André B. 1; Sánchez, Jeria, Hernán F. 1; Valenzuela Silva Cristian A.1. 1Laboratorio de Antropología Física y Anatomía Humana. Instituto de Biología. Pontificia Universidad Católica de Valparaíso, Chile. 2Universidad de Chile, Instituto de Nutrición y Tecnología de los Alimentos (INTA). 3RS-Brasil.

Introducción: Uno de los deportes que ha tomado mas fuerza en nuestro país, y que se represento con el campeonato sudamericano realizado el año 2007 en Chile, es el voleibol. En esa oportunidad tuvimos la posibilidad de tener a algunos de los mejores equipos 
del mundo, entre ellos al campeón mundial, Brasil. En esta ocasión, Chile, no pudo lograr buenos resultados probablemente por las diferencias antropométricas en comparación con los otros equipos extranjeros, los cuales al poseer una estatura mayor son capaces de saltar más y llegar más alto sobre la malla, una ventaja comparativa sobre sus rivales. La caracterización de estos equipos, favorece un trabajo más eficiente para el logro de buenos resultados. Es por eso que hemos evaluado a la selección juvenil de Chile, para contar con cuadros comparativos de composición corporal y somatotipos que se podrán ir moldeando a edades temprana. Sujetos y método: Se evaluaron un total de 35 jugadores profesionales de de 4 selecciones que participaron del sudamericano de voleibol realizo el año 2007 en Chile. Las selecciones evaluadas fueron de Paraguay, Uruguay, Colombia y el vicecampeón Venezuela. También ha sido evaluada, la selección juvenil de Chile $n=12$ jugadores varones. Se evaluó bajo el protocolo de marcaje y medición de la International Society for the Avancement in Kineanthropometric (ISAK) en condiciones normales de temperatura, a primera hora de la mañana y después del vaciado urinario, por evaluadores con licencia nivel II de ISAK. El protocolo de las variables evaluadas se utilizan para las formulas de composición corporal de D. Kerr (1988) y para el método antropométrico del Somatotipo de Heath-Carter (1990) Para dichas medidas y protocolo se usó un kit antropométrico Rosscraft SRL validado por la ISAK que incluye antropómetros óseos, huincha métrica y plicómetro o calibre para pliegues. Resultados: Se obtuvieron diferencias especialmente en los componentes muscular y graso, donde el equipo de Venezuela fue el que obtuvo mayor cantidad de músculo y menor de grasa. En todos los equipos se mostró una promedio de estatura elevado y de edad joven. El somatotipo de obtenido de todos los grupos fue de mesoectomorfico, es decir que el componente predominante es el muscular y secundariamente el óseo. En el seleccionado Juvenil de Chile, encontramos somatotipos de tendencia próxima a los equipos profesionales extranjeros y si mismo valores de composición corporal, lo cual nos augura que estaríamos en presencia de un equipo promisorio nacional. Conclusiones: Las diferencias entre los componentes estructurales fueron más claras con respecto al grupo de Venezuela, el cual poseía una mayor estatura, más masa muscular y menor cantidad grasa, lo que mejora la eficiencia mecánica de este deporte, logrando un rendimiento mejor frente a los otros equipos. Esto se representa con el resultado obtenido por este equipo, el cual solo perdió en la final del campeonato, logran- do ser vice campeón Sudamericano detrás de Brasil. En el seleccionado Juvenil de Chile, encontramos somatotipos de tendencia próxima a los equipos profesionales extranjeros y si mismo valores de composición corporal, lo cual nos augura que estaríamos en presencia de un equipo promisorio

\author{
Palabras clave: Voleibol - Masculino - \\ Morfoestructura - Somatotipo \\ Financiado por Dirección Investigación. Labo- \\ ratorio de Antropología Física y Anatomía Humana. \\ Pontificia Universidad Católica de Valparaíso. Chile
}

MORFOESTRUCTURA DE JUGADORAS CHILENAS DE FÚTBOL FEMENINO. Rodríguez Rodríguez Fernando J.1; Almagià Flores Atilio A. 1; Barraza Gómez Fernando O. 1; Lizana Arce Pablo J1. Jorquera Aguilera Carlos A2. Ivanovic Marincovic Daniza M3. Binvignat Gutierrez Octavio1-4. 1Laboratorio de Antropología Física y Anatomía Humana. Instituto de Biología. Pontificia Universidad Católica de Valparaíso, Chile. 2Escuela de Nutrición, Facultad de Medicina, Universidad Mayor, Chile. 3Universidad de Chile, Instituto de Nutrición y Tecnología de los Alimentos (INTA). 4RSBrasil.

El fútbol femenino ya ha superado los 40 millones de jugadoras en el mundo en 15 años, sobrepasando así al fútbol juvenil masculino. Y es que la cifra anterior no es menor, sobre todo si se piensa que son casi 120 millones los jugadores de todas las categorías que componen hoy el fútbol masculino. El mundial de fútbol femenino sub 20 en nuestro país ha suscitado gran atención sobre los factores que podrían mejorar el rendimiento físico y los cambios estructurales de las jugadoras. Conociendo la relación entre algunos componentes de la condición física y la morfoestructura, analizaremos y discutiremos los factores antropométricos de jugadoras de fútbol de nuestro país. Se evaluaron un total de 43 jugadoras de fútbol, 26 seleccionadas chilenas sub 20 y 17 jugadores del plantel campeón 2007 de la Pontificia Universidad Católica de Valparaíso, todas ellas bajo su consentimiento informado. Se evaluó bajo el protocolo de marcaje y medición de la International Society for the Avancement in Kineanthropometric (ISAK) en condiciones normales de temperatura, a primera hora de la mañana y después del vaciado urinario, por evaluadores con licencia nivel II de ISAK.Las variables medidas fueron peso, estatura de pie, estatura sentado, perímetros musculares, diámetros óseos y 
pliegues cutáneos. Todas estas medidas se utilizan para las formulas de composición corporal de D. Kerr (1988) y para el método antropometrico del Somatotipo de Heath-Carter (1990) Para dichas medidas y protocolo se usó un kit antropométrico Rosscraft SRL validado por la ISAK que incluye antropómetros óseos, huincha métrica y Plicómetro o calibre para pliegues. Al comparar los dos grupos, encontramos diferencias y similitudes. Estas últimas consisten en el IMC que en ambos grupos se encuentra dentro de lo que la OMS considera como una condición nutricional "Normal", y masa ósea y masa de piel. Existe una diferencia de 3,4 años entre ambos grupos lo que diferencia algunos otros componentes de la morfoestructura como una mayor cantidad de grasa y menor cantidad de músculo del grupo sub-20 en comparación con el grupo PUCV y una representación grafica del somamtotipo que corrobora estas diferencias. Las Diferencias en los componentes de la composición corporal entre ambos grupos tienen dos razones fundamentales. La primera por el mayor desarrollo y maduración física del grupo PUCV quien al ser mayor, tiene promedios de estatura y peso también mayores. La segunda razón es el nivel de entrenabilidad de del grupo PUCV, que al tener $\mathrm{n}$ mayor desarrollo permite la realización de entrenamientos las prolongados y de mayor intensidad, demostrando un mayor desarrollo muscular y menor cantidad de grasa en comparación con grupo sub-20. Concluimos que según los factores antropométricos el grupo PUCV es capaz obtener un rendimiento deportivo mayor que el grupo sub-20, siendo esto un fundamento al momento de elegir a las jugadoras pre seleciondas nacionales.

Palabras clave: Futbol - Femenino Morfoestructura - Somatotipo

Financiado por la Dirección Investigación. Laboratorio de Antropología Física y Anatomía Humana. Pontificia Universidad Católica de Valparaíso. Chile

MORFOMETRÍA DE LA GLÁNDULA PINEAL HUMANA EN CONCEPCIÓN, VIII REGIÓN, CHILE. Morphology of the human pineal gland in Concepción, VIII Region, Chile. Maurelia, MA.; Fritz, O.; Serrano, F.; Oviedo, G.; Figueroa, L.; Epelde, N. Universidad de Concepción.

Introducción: La glándula Pineal está ubicada en el encéfalo por sobre los calículos anteriores en la línea media, se considera una glándula endocrina la cual presenta una neurosecreción la melatonina, su morfometria no a sido debidamente estudiada, según Ferreira 2004, la glándula mide $3 \mathrm{~mm}$ de ancho. Material y método: Fueron medidas 20 glándulas pineales, obtenidas de encéfalos humanos donados al departamento de Anatomía Normal de la Universidad de Concepción desde los años 2003 al 2008 utilizando un Caliper y midiendo el largo desde la base al ápice de la glándula, el ancho desde la región más convexa desde sus bordes derecho a izquierdo y el espesor en la región más convexa desde su cara anterior a posterior, los resultados fueron estudiados mediante el software Epidat 2.0. Resultados: El promedio del largo de la glándula fue de $8,12 \mathrm{~mm}$, donde el $64 \%$ se encontraba entre 7 a $9 \mathrm{~mm}$; El promedio del ancho de la glándula Pineal fue de 6,54, donde el $65 \%$ media entre 6 a $8 \mathrm{~mm}$; Y el promedio de la profundidad de la glándula fue de $3,44 \mathrm{~mm}$ donde el $50 \%$ media entre 3 a $4 \mathrm{~mm}$ de longitud. Conclusiones: La glándula Pineal Humana presenta una forma lenticular que varía en cada muestra desde 5,31 $\mathrm{mm}$ hasta $9,15 \mathrm{~mm}$ de largo, por lo que se hace necesario averiguar por medio de la histomorfometria si los tamaños celulares varían o es el número de células el que cambian.

Melatonina

Palabras clave: Glándula Pineal, Morfometria,

MORFOMETRÍA Y ULTRAESTRUCTURA DEL EFECTO DE ESTIMULACIONES CRECIENTES DE LASER INFRARROJO SOBRE HEPATOCITOS DE RATA. Morphometry and Ultrastructure of the Effect of Increasing Stimulations Infrared Laser on Rat Hepatocytes. Cornejo, R.; Matamala, F.; Silva, H. Universidad de La Frontera, Temuco. Chile.

El láser infrarrojo es utilizado con éxito en el tratamiento de lesiones articulares debido a su probada acción analgésica, antiinflamatoria y cicatrizante, promoviendo de igual manera a nivel celular tanto una drástica activación en la síntesis de ATP mitocondrial como de síntesis proteica y estimulando además los eventos conducentes a la división celular. Se irradiaron 8 ratas en cuatro puntos del hígado durante 15 días consecutivos con dosis de: 2, 4, 8 y 16 Joules/cm2 manteniendo otras 4 ratas como control. Tanto de las ratas control como de las irradiadas fueron obtenidas muestras de hígado las cuales fueron tratadas con la técnica para microscopía electrónica de transmisión. De hepatocitos normales (controles) e irradiados con estas diferentes intensidades, se obtuvieron micrografías electrónicas de transmisión con aumentos finales de $11.000 \mathrm{X}$ y realizándose en ellas técni- 
cas morfométricas con el propósito de determinar aspectos cuantitativos relativos a los componentes pertenecientes a dichas células y establecer diferencias morfológicas entre ellas, evaluando entonces, el rol de las distintas estimulaciones infrarrojas. Se evaluaron fracciones volumétricas de: núcleo, citoplasma, retículo endoplásmico rugoso, mitocondrias, gránulos de glicógeno, nucleolo, eu y heterocromatina. De igual manera se evaluó la relación núcleo - citoplasmática y el área de cada célula. Los resultados derivados del estudio morfométrico comparativo entre hepatocitos normales e irradiados con intensidades crecientes indican que existen diferencias significativas en las evaluaciones de todos los parámetros celulares citados. El análisis de los respectivos resultados, permiten concluir que las estimulaciones infrarrojas modifican estos parámetros celulares evaluados, lo que indicaría una modificación importante en la función celular.

Palabras clave: Hepatocitos; Láser Infrarrojo; Morfometría; Ultraestructura.

Financiado por Proyecto DIUFRO № $08-0022$

NERVIO ALVEOLAR INFERIOR (NAI) DE SUS
SCROFA DOMESTICA COMO MODELO DE ESTU-
DIO EN ODONTOLOGÍA. Inferior Alveolar Nerve in Sus Scrofa Domestica as study's model in dentistry. Ruíz Osvaldo, CD. Matamala Fernando, Bastías Claudio. Facultad de Medicina, Unidad de Anatomía, Magister en Morfología, U. de La Frontera, Chile

El propósito de este trabajo fue validar el NAI de Sus Scrofa (cerdo doméstico) como modelo de estudio, mediante la disección y estudio radiográfico de su recorrido intramandibular, para responder a la necesidad existente de una mayor casuística y adquisición de destrezas, en la formación anatómica de nuevos odontólogos. Objetivo: Disecar y describir el recorrido intramandibular del NAI de Sus Scrofa doméstica, correlacionado su morfometría real con la obtenida a través de una Rx extraoral. Material y método: 10 mandíbulas de Sus Scrofa de edades entre los 12 y 16 meses. Se disecó cada mandíbula, luego fue radiografiada con en placas extraorales. Luego se procedió a la disección y morfometría del NAI en el canal mandibular. Disecado el NAl se procedió a cubrirlo con una mezcla de pintura acrílica y limalla metálica para ser radiografiados y comparar la morfometría de disección del nervio con la obtenida radiográficamente. Resultados: El resultado nos indica que el nervio se encuentra rodeado por gran cantidad de tejido que rellena el lumen de canal, una arteria y dos venas, es una estructura central con ramos hacia las piezas dentarias así como 2 ramos que perforaban la tabla externa mientras que el tronco que se continua por el interior de la mandíbula hacia los incisivos. Su diámetro promedio a la altura del trígono retromolar es 3.30 $\mathrm{mm}$, en la parte media del canal mandibular disminuye a $3.00 \mathrm{~mm}$ y al dar sus ramos terminales perforantes es de $1.70 \mathrm{~mm}$. Su longitud desde su ingreso al canal hasta dividirse en sus ramos terminales es de $72 \mathrm{~mm}$, medidas que concuerdan con las obtenidas mediante las Rx. Conclusiones: Las coincidencias estructurales de la disposición del nervio así como del paquete vascular en conjunto con un canal mandibular amplio nos permiten proponer al NAI de Sus Scrofa como un modelo de estudio de gran valor en el ámbito de la odontología. Además las Rx extraorales sirven como elemento juicio para realizar morfometrías aplicables.

Palabras clave: Sus Scrofa, Nervio Alveolar Inferior, Canal Mandibular

\section{PERFIL ANTROPOMETRICO DE SELECCIONADOS SUDAMERICANOS DE VOLEIBOL PROFESIONAL.}

Anthropometric profile of a south american professional volleyball team. Rodríguez Rodríguez Fernando J.1; Almagià Flores Atilio A. 1; Barraza Gómez Fernando O. 1; Lizana Arce Pablo J. 1; Ivanovic Marincovic Daniza M. 2; Binvignat Gutiérrez Octavio1-3. 1Laboratorio de Antropología Física y Anatomía Humana. Instituto de Biología. Pontificia Universidad Católica de Valparaíso, Chile. 2Universidad de Chile, Instituto de Nutrición y Tecnología de los Alimentos (INTA). 3RSBrasil.

La antropometría en los aspectos deportivos, se ha empleado para la predicción del rendimiento físico. La prioridad de un componentes estructural sobre otro podría definir una mejor aptitud deportiva,. Los jugadores de voleibol requieren de condiciones físicas especiales como una gran altura y menos grasa y más masa muscular para alcanzar más altura de salto y mayor potencia en los golpes, aspectos que se analizan en nuestro trabajo. Sujetos y método: 35 jugadores profesionales de de 4 selecciones que participaron del sudamericano de voleibol realizo el año 2007 en Chile. Las selecciones evaluadas fueron de Paraguay, Uruguay, Colombia y Venezuela. Se evaluó bajo el protocolo de International Society for the Avancement in Kineanthropometric (ISAK), por evaluadores con licencia nivel II de ISAK. Se utilizan las formulas de composición corporal de D. Kerr (1988) y para el método 
antropometrico del Somatotipo de Heath-Carter (1990) .Se usó un kit antropométrico Rosscraft SRL validado por la ISAK. Se obtuvieron diferencias especialmente en los componentes muscular y graso, donde el equipo de Venezuela fue el que obtuvo mayor cantidad de musculo y menor de grasa. En todos los equipos se mostro una promedio de estatura elevado y de edad joven. El somatotipo de obtenido de todos los grupos fue de Meso-ectomorfico. El componente predominante es el muscular y secundariamente el óseo. Las diferencias entre los componentes estructurales fueron más claras con respecto al grupo de Venezuela, el cual poseía una mayor estatura, mas masa muscular y menor cantidad grasa, lo que mejora la eficiencia mecánica de este deporte, logrando un rendimiento mejor frente a los otros equipos. Esto se representa con el resultado obtenido por este equipo, el cual solo perdió en la final del campeonato, logrando ser vice campeón Sudamericano detrás de Brasil.

Palabras clave: Voleibol - Masculino Morfoestructura - Somatotipo

Financiado por Dirección Investigación. Laboratorio de Antropología Física y Anatomía Humana. Pontificia Universidad Católica de Valparaíso. Chile

\section{PERFIL DOS NASCIDOS VIVOS COM FENDA LA- BIAL E FENDA PALATINA, NO BRASIL, NO PERÍO- DO DE 1999 A 2005. Amanda Brilhante Pontes1; Bianca Angelina Macêdo Do Nascimento1; Cássia Camarinha Da Silva1; Giselle Jones Ohana1; Karla Lima Lopes1; Layza Costa Ribeiro2; 1Universidade Federal Do Pará; 2Universidade Do Estado Do Pará. Brasil.}

As fendas do lábio superior e do palato são comuns e especialmente conspícuas, pois resultam em um aspecto facial anormal e defeitos na fala. Consistem em anomalias genéticas que ocorrem durante a formação e o desenvolvimento do embrião (do final da $6^{a}$ até o início da $9^{\mathrm{a}}$ semana), tendo a fossa e a papila incisivas como marcos de referência. Podem ser anomalias na fenda anterior - incluem as fendas labiais com ou sem fendas na porção alveolar da maxila e resultam de uma deficiência do mesênquima da(s) saliência(s) maxilar(es) e do segmento intermaxilar e anomalias na fenda posterior - incluem as fendas do palato secundário ou posterior que se estendem pelas regiões moles e duras do palato até a fossa incisiva, separando as partes anterior e posterior do palato. Sendo assim, se faz importante realizar uma pesquisa com o objetivo de quantificar os casos de nascidos vivos com essas anomalias, pois há escassez na literatura de tais dados e, os poucos encontrados, mostram altas incidências. Trata-se de um estudo de caráter descritivo, retrospectivo e de fonte secundária. Os dados foram obtidos através do banco de dados do Departamento de Informação do Sistema Único de Saúde (DATASUS) e são referentes ao Sistema de Informações sobre Nascidos Vivos com Anomalias Congênitas, com ênfase em Fenda Labial e Fenda Palatina, no Brasil no período de 1999 a 2005. Foram observados 9.104 casos de nascidos vivos com tais anormalidades no período estudado $(0,04 \%$ do total de nascidos vivos no Brasil no mesmo período), sendo $59,2 \%$ do gênero masculino; quanto à idade da mãe, a maioria tinha de 20 a 24 anos (29\%), seguidas daquelas de 25 a 29 anos (23\%). Com relação à gestação, $85,8 \%$ duraram de 37 a 41 semanas e $9,7 \%$ de 32 a 36 semanas. Mais da metade das mães realizou 7 ou mais consultas pré-natais $(51,7 \%)$ ou 4 a 6 consultas pré-natais $(32,3 \%)$. Prevaleceram a gravidez única $(97,6 \%)$ e o parto do tipo vaginal $(52,7 \%)$, seguido do parto cesáreo (47\%). As Unidades Federativas com mais casos foram São Paulo $(28,4 \%)$, Rio Grande do Sul $(8,8 \%)$ e Minas Gerais $(8,4 \%)$. Verificou-se que os casos de nascidos vivos com fenda palatina têm números relevantes e apresentam gravidade significativa quando se considera as conseqüências às quais as crianças com tais anomalias estão expostas. O tratamento é importante e o custo resultante dos casos de fenda palatina em termos de morbidade, cuidados de saúde, distúrbios emocionais, sociais e exclusão do trabalho são consideráveis para o indivíduo, sua família e a sociedade. Assim, é importante seu diagnóstico precoce por meio da detecção no pré-natal através da ultra-sonografia, a investigação de anormalidades associadas e o tratamento adequado através de um programa de recuperação multidisciplinar.

\section{PREPARO DE PEÇAS ANATÔMICAS COM SOLUÇÃO DE LARSSEN MODIFICADA E DESIDRATADAS POR IMPREGNAÇÃO EM ALCOO.}

Pádua, Arlysson Campos; Godoy, José Roberto; Silva Júnior, Waltercídes.

O estudo da anatomia depende da utilização de peças anatômicas provenientes de cadáveres. O preparo destas peças ainda é uma prática artesanal, que demanda tempo e gastos com o material utilizado no preparo de soluções para conservação de cadáver; existe também a necessidade de evidenciar as 
estruturas que serão estudadas. Várias técnicas se mostram eficientes para a produção de peças anatômicas, porém demandam custos financeiros relativamente altos, além da pouca durabilidade dessas. A modificação de soluções de conservação de cadáveres para o preparo de peças anatômicas tem o cunho de produzir material durável a um baixo custo financeiro. Desta forma, o presente trabalho tem como objetivo apresentar o resultado final da utilização de soluções alternativas na conservação de peças anatômicas visando baixo custo e alta durabilidade. Metodologia: Foram utilizados 3 animais: preá, ovelha recém nascida e coelho. Inicialmente foi efetuada a lavagem do circuito cardiovascular com a solução salina e posteriormente realizada uma nova perfusão com formol a $10 \%$ misturado com corante vermelho e em seguida o óleo vegetal com acido bórico. A peça é então dissecada e desidratada por impreguinação em álcool. O estudo foi aprovado pelo Comitê de Ética em Pesquisa da Faculdade JK. Resultados: observa-se a manutenção da cor natural dos tecidos no material produzido, bem como a morfologia muscular e visceral. Conclusão: esta técnica mostra-se viável para a produção de peças anatômicas duráveis sem a necessidade de estarem submersas em qualquer solução fixadora. Mostra-se como uma técnica simples de ser aplicada e extremamente econômica financeiramente, pois os reagentes utilizados na fórmula são de custo baixo e fácil acesso.

\section{RADIOGRAFIA POSTERO-ANTERIOR DE WATERS Y SU CORRELACION ANATOMO-RADIOLOGICA.} Blanchet Verónica L.; González M. A.; Casco N. S.; Blanchet María J. Director: Dra. Wetzel Rosa E. Cátedra I de Anatomía Humana Normal e Imagenología: Prof. Civetta, J D. Facultad de Medicina. UNNE. Corrientes, Argentina. C.P. 3400. Sargento Cabral 2001.

El presente trabajo tiene como objetivo evaluar las dificultades que surgen en la interpretación de radiografías en proyección postero-anterior de Waters, por la superposición de planos óseos, con el fin de disminuir errores diagnósticos en este tipo de estudios. Dada la poca disponibilidad de otros métodos diagnósticos de mayor complejidad en nuestra zona y la alta frecuencia de patologías rinosinusales, se desprende la importancia de su estudio. Materiales y Métodos: Este trabajo es de tipo descriptivo, donde se utilizaron 40 placas radiográficas en posición posteroanterior de Waters de pacientes adultos de ambos sexos; 8 cortes sagitales de cráneo en piezas cadavéricas de adultos de ambos sexos formalizadas al $10 \%$; 10 cortes coronales de cráneo en piezas cadavéricas de adultos de ambos sexos formalizadas al $10 \%$. Se registró gráficamente con fotografías panorámicas y focalizadas, y se esquematizaron y tabularon los datos. Resultados: En esta incidencia se observa: los senos etmoidales, por detrás la proyección del cuerpo del esfenoides; los senos maxilares, luego la proyección de los huesos de la pared inferior de la orbita (proceso cigomático de la maxila, proceso frontal del hueso cigomatico y proceso orbitario del hueso palatino) y sobre estos últimos notamos el foramen infraorbitario y el agujero redondo. En la cavidad nasal se evidencia el septo de la nariz, hueso nasal, proceso frontal de la maxila y las conchas nasales. A nivel de la cavidad bucal se observa el diente del axis. Conclusión: Los resultados obtenidos demuestran una constante en el orden antes mencionado lo que produce una superposición ósea característica que permite la localización de los diferentes componentes anatómicos con mayor facilidad, señalando la vigencia de esta incidencia en nuestro medio, para la interpretación diagnostica de patologías de la vía aérea respiratorias y traumatismos craneofaciales.

Palabras clave: Radiología - Proyección postero-anterior de Waters - Senos Paranasales

RELATIONSHIP BETWEEN CORACOID PROCESS AND MUSCULO CUTANEOUS NERVE. GuedesCorrêa, J. F.1, M.D., Phd; Siquara, A. C. M.2 1José Fernando Guedes-Corrêa, Neurosurgery Section, Hospital Universitário Gaffrée \& Guinle; Anatomy Department, Universidade Federal do Estado do Rio de Janeiro (UNIRIO). Escola de Medicina e Cirurgia (EMC). Universidade Federal do Estado do Rio de Janeiro (UNIRIO), Rio de Janeiro, Brazil. 2Ana Caroline Moura Siquara, Graduate in Medicine EMC/ UNIRIO, Scholarshiper IC/UNIRIO. Escola de Medicina e Cirurgia (EMC). Universidade Federal do Estado do Rio de Janeiro (UNIRIO), Rua Frei Caneca, n 94 Disciplina de Anatomia Humana - Centro - 22211040, Rio de Janeiro, RJ - Brazil

The subcoracoid space is the space between the coracoid process' extremity and humerus head. It is occupied by subcoracoid bursa and superior subescapular recess, the gleno-humeral articulation capsule, the subescapular tendon and the subacromial bursa. This space can be reduced as consequence of wearing in rotator cuff tendons, local tissue pathology, iatrogenic lesion or congenital anomalies, causing pain 
around or near the coracoid process (anterior pain at the shoulder), the "subcoracoid space syndrome". The treatment is surgical, with anterior access to the shoulder. The anatomy of the anterior shoulder is complex and anatomical variations that can difficult the surgical access are reported, especially in neurovascular structures. The musculocutaneous nerve is an example. Our objective is to show the anatomical relationship between the musculocutaneous nerve and the coracoid process. Methods and results: Three articles $(1,2,3)$ were selected; two measured $(1,2)$ the distance between the coracoid process and the entrance point of the musculocutaneous nerve at the coracobrachialis muscle, and one(3) measured the distance between the coracoid process and the 1st branch of muscolucatenous nerve to biceps brachial muscle. In article 1 the average distance was 49,28 $\mathrm{mm}$ (standard deviation of $9,72 \mathrm{~mm}$ ); in article 2 the average distance was $56 \mathrm{~mm}$ and the standard deviation wasn't calculated; the average distance of these articles is $52,64 \mathrm{~mm}$. In article 3 the average distance was $122 \mathrm{~mm}$ and the standard deviation was $12 \mathrm{~mm}$. Ten cadaveric upper-limb specimens disarticulated at the shoulder were dissected and the distance between the exit point of musculocutaneous nerve at coracobraquialis muscle and the 1st branch of musculocutaneous nerve to biceps muscle was calculated. The average distance is $33,1 \mathrm{~mm}$ and the standard deviation is $15,1 \mathrm{~mm}$. Conclusion: Injury to musculocutaneous nerve in anterior shoulder surgery can happen if its entrance point in the coracobrachialis muscle is higher than expected (less than $50 \mathrm{~mm}$ ); The main reference points in surgery access to anterior shoulder and upper limb surgeries can be the coracoid process, coracobrachialis muscle and biceps brachial muscle; The average distance of musculocutaneous nerve is $52 \mathrm{~mm}$ (from coracoid process to coracobrachialis muscle) and $33 \mathrm{~mm}$ (from coracobrachialis muscle to biceps muscle).

\section{REPAROS ANATOMICOS DE RELEVANCIA EN IMPLANTOLOGIA ODONTOLOGICA CONVENCIO- NAL EN CONCEPCION, VIII REGION, CHILE.}

Repairs anatomy of relevance in implantology odontológica convencional in Concepcion, VIII Region, Chile. Figueroa, L.; Maurelia, MA.; Serrano, F.; Oviedo, G.; Epelde, N. Universidad de Concepción, Universidad San Sebastián

La práctica implantológica consiste en reemplazar piezas dentarias pérdidas con materiales aloplasticos, que deben integrarse biológicamente y funcionar en un ambiente secuelado, donde estructuras vecinas pueden servir como apoyo o dificultar gravemente la colocación de implantes convencionales. Se realizaron observaciones en cortes tomográficos y reconstrucciones virtuales 3D sin distorsión de 30 pacientes adultos entre 25 y 45 años, utilizando software de interpretación radiográfica I-Cat Vision, de conducto dentario mandibular, agujero mentoniano, conducto incisivo, seno maxilar y piso de fosas nasales, midiendo sus dimensiones, espesores óseos, grosor de corticales, observando las relaciones con ápices de piezas dentarias vecinas. Estructuras anatómicas normales tales como el seno maxilar presentan una estrecha relación con los ápices de piezas dentarias, especialmente a nivel de premolares y molares. En el caso de la mandíbula, se observa una variabilidad en la posición del conducto dentario, así como en su diámetro y espesor de cortical. Conclusiones: Los valores obtenidos en pacientes dentados naturales entregan una valiosa información para entender los parámetros óseos normales que se presentan en relación a las piezas dentarias, así como sus variaciones, lo que nos ayuda a entender situaciones de edentulismo parcial y total, donde el análisis e interpretación correcta de los estudios que muestran reparos anatómicos es vital con el fin evitar accidentes que obstaculicen la practica implantologica.

Palabras clave: Implantes convencionales, Conducto Dentario, Agujero Mentoniano, Seno Maxilar.

\section{REVISIÓN ANATÓMICA DE LAS INSERCIONES DEL} MÚSCULO FIBULAR LARGO. Oviedo, Jorge Matías; Samaniego Aquino, Franco Antonio; Garcilazo, Emiliano Lucas Nahuel; Maldonado, Noelia

El músculo fibular largo se sitúa en el plano superficial de la región lateral de la pierna. Se extiende desde el tercio superior de la fíbula y tibia, tomando un trayecto descendente oblicuo de medial a lateral, formando un tendón penniforme que pasa detrás del maléolo lateral. El tendón se acoda al llegar al borde externo del pie e ingresa a un surco en el hueso cuboides. A este punto el tendón presenta un ensanchamiento fibrocartilaginoso que puede dar lugar a un hueso sesamoideo denominado "Os Peroneum". Luego continúa su trayecto atravesando la planta del pie para llegar a su inserción en la base del primer metatarsiano. Este estudio tiene el objetivo de obtener un registro de la incidencia de las variedades anatómicas del músculo en nuestra región, el Nordeste Argentino. El diseño de trabajo es de tipo descriptivo, 
por lo que se procedió con la numeración y conformación de un registro del total de material empírico disponible como así también de las variedades halladas. Fueron utilizadas 27 piezas cadavéricas adultas de ambos sexos conservadas en solución de formol al $10 \%$, disecadas con la técnica clásica e instrumentación convencional. Los hallazgos fueron documentados por medios fotográficos, panorámicos y focalizados. El total de los datos fue clasificado y tabulado, sometiéndose luego a procesos estadísticos que se representaron gráficamente. Las variedades encontradas son: Variedad I: $48,14 \%$, descrita por Rouvière como clásica; sus inserciones fueron antes mencionadas. El resto de las variedades fueron descritas por Macalister, de las cuales fueron halladas las siguientes: Variedad II: 7,4\%; se inserta por tres tendones: uno en el quinto, tercer y primer metatarsiano. Variedad III: 29,6\%; que consiste en un hueso sesamoideo verdadero. Se halló una pieza $(3,07 \%)$ con un tipo de variedad no registrada en las referencias bibliográficas, se trata de una bifurcación del tendón, a partir de la cual un haz se inserta inmediatamente por detrás de la inserción del tendón del músculo fibular corto, mientras que el otro haz continúa su trayecto hasta la base del primer metatarsiano. En base a los datos recolectados, puede inferirse que las variedades consideradas como clásicas para Rouvière no presentan una mayor incidencia que las descritas por Macalister en nuestra región. Con respecto al Os peroneum, esta variedad representa el mayor porcentaje de las descritas por Macalister.

\section{REVISION DE VARIANTES DEL MÚSCULO BICEPS} FEMORAL. Revision of variety of biceps femoris muscle. Sosa, M. A.; Vidal, G. A.; Sosa, E. A.; De Miranda Dos Santo, N. Cátedra I de Anatomía Humana Normal e Imaginología. Prof. J. D. Civetta. Sargento Cabral 2001. CP 3400. TEL: 054-03783-423478. Facultad de Medicina. UNNE. Corrientes. Argentina. sosamatias@hotmail.com

El músculo bíceps femoral (MBF) se encuentra en la región posterior del muslo situado en el plano superficial. Se compone de dos porciones, una cabeza corta que se origina en el intersticio de la línea áspera y una cabeza larga que se origina en la cara posterior de la tuberosidad isquiática, estas se reúnen y se insertan a través de un tendón en el vértice de la cabeza de la fíbula. El objetivo del trabajo fue la revisión de variantes del bíceps con criterio de proyección pedagógica y para su utilización en la práctica medico quirúrgica. El diseño utilizado co- rresponde al tipo descriptivo. Se utilizaron piezas cadavéricas correspondientes a veinte miembros inferiores de adultos, ambos sexos, conservados en solución acuosa de formaldehído al $10 \%$, se realizó biometría y disecó con técnicas e instrumentos convencionales. Se realizó registros fotográficos panorámicos y focalizados. A los datos obtenidos se aplicaron métodos estadísticos, tabularon y graficaron. La observación del material emperico muestra: Variedad I: se compone de dos porciones, una cabeza corta que se origina en el intersticio de la línea áspera, una cabeza larga que se origina en la cara posterior de la tuberosidad isquiática, ambas se reúnen y terminan en un tendón común en el vértice de la cabeza de la fíbula. 19 (95\%). Variedad II: cabeza corta ausente $(0 \%)$. Variedad III: una segunda cabeza larga desde la tuberosidad isquiática $(0 \%)$. Variedad IV: tercera cabeza que surge de la parte superior de la línea áspera $(0 \%)$. Variedad V: una tercera cabeza que nace del cóndilo del fémur. $1(5 \%)$. Variedad VI: tercera cabeza que va cubierta por la fascia del músculo glúteo máximo, como un haz redondeado, que se une a la cabeza larga. (0\%). Variedad VII: tercera cabeza que va desde la fascia lata hasta la parte superior de la línea áspera $(0 \%)$. Variedad VII: la cabeza corta puede recibir un fascículo accesorio del músculo vasto lateral (0\%). Estos resultados nos permitirían tener un conocimiento de la prevalencia de las formas de presentación del músculo bíceps femoral en nuestro medio y poder comparar los resultados obtenidos en las distintas zonas geográficas.

Palabra clave: Miología, músculo bíceps femoral, variación anatómica.

\section{REVISIÓN Y DESCRIPCIÓN DE LAS VARIEDADES ANATÓMICAS DEL ORIGEN DEL MÚSCULO REC- TO FEMORAL Y SU RELACION CON EL DEPORTE.}

Anatomical review and description of rectus femoris and the relation with sports. Fernández Picchio G., Sero B., Maldonado F. Director: Dr. Bergottini C.H. Cátedra I de Anatomía Humana Normal e Imagenología. Prof. J.D.Civetta. Facultad de Medicina U.N.N.E. Sgto. Cabral 2001. C.P.:3400. Corrientes, Argentina. Email: gastonfp1@hotmail.com

El presente trabajo es un estudio del origen del músculo recto femoral del muslo que pretende corroborar conocimientos anatómicos y su aplicación en las patologías trauma-ortopédicas. El origen consta de dos tendones, el directo que se inserta en la espina 
iliaca anterior inferior y el reflejo en el surco supraacetabular. El objetivo fue describir detalladamente su morfología y las variables más relevantes en relación a su función en la contracción excéntrica. El diseño es del tipo descriptivo se utilizaron 31 piezas cadavéricas adultas, de ambos sexos fijadas con formaldehído (10\%). Se utilizo técnicas y material de disección convencional de hemipelvis y región proximal de muslo. Se registró el material empírico en fotografías panorámicas y focalizadas. Se aplicó métodos estadísticos que se graficaron. El análisis del material empírico muestra en 28 piezas (90\%), la variedad clásica (Rouviêre), que describe los 2 tendones, el directo con fibras a la espina iliaca anterior inferior y el reflejo al surco supraacetabular. En 2 piezas (10\%), la variedad 2 (Testut), la cual describe ausencia del origen del tendón reflejo. La variedad 3 (Testut Bergman), que detalla la unión de las 2 cabezas de origen a 4 centímetros por debajo de la cavidad acetabular no se constato en nuestro medio; al igual que la variedad 4 (Macalister), que describe un origen en la espina iliaca anterior superior. Se ha producido material de información básica para fundamentar las prácticas clínico-quirúrgicas y las lesiones deportivas. Se ha corroborado las distintas variedades de presentación de origen del músculo recto femoral. Además, se ha producido piezas anatómicas de uso docente en la cátedra.

Palabras clave: Anatomía. Tenomiología. Recto femoral. Inserciones.

Financiado por: U.N.N.E

\section{REVISIÓN Y DESCRIPCIÓN DE LAS VARIEDADES} DEL MÚSCULO ABDUCTOR LARGO DEL PULGAR.

Description and review of the varieties of abductor muscle Pollicis Longus. Fedorchuk, D. G; Ford María L; Expucci, M. V.; Salas, Gabriela B. Director: Bergottini, C. H. Cátedra I de Anatomía Humana Normal e Imagenología. Profesor Dr. Civetta, J. D. Facultad de medicina UNNE. Sargento Cabral 2001, Corrientes Capital (3400). Republica Argentina. E-mail: ferchu_dgf@hotmail.com.

El músculo abductor largo del pulgar es el más lateral del plano profundo del grupo muscular posterior del antebrazo. Se origina en la cara posterior de la ulna y el radio, y también en la membrana interósea del antebrazo. Desciende oblicuamente por encima del carpo continuándose con un tendón que se inserta en la cara lateral de la extremidad superior del primer hueso metacarpiano.
Palabras clave: Región ante-braquial; Posterior; Músculo; Abductor Largo del Pulgar.

SEX DETERMINATION IN MANDIBLES IN THE FIRST YEAR OF LIFE BY A QUANTITATIVE APPROACH. Determinación del sexo en mandíbulas en el primer año de vida mediante una aproximación cuantitativa. Suazo G.I.C 1, 2; Zavando M.D.A1; Smith R.L2. 1Departamento de Anatomía Normal, Universidad de Talca 2Departamento de Morfología y Genética. Universidad Federal de Sao Paulo, SP., Brasil.

Numerosos estudios han demostrado que las características esqueletales varían en las distintas poblaciones. Diversos autores indican que es posible la determinación del sexo en mandíbulas a partir de los siete meses de edad, sin embargo existen escasos estudios morfométricos realizados en mandíbulas de niños brasileros. El propósito de este estudio es analizar distintas dimensiones de mandíbulas de niños brasileros y determinar aquellas de utilidad en el diagnóstico forense del sexo. Para éste estudio se utilizaron 32 mandíbulas de niños brasileros de entre 0 y 1 año de edad, de sexo conocido, pertenecientes a la colección de cráneos de la Universidad federal de Sao Paulo (UNIFESP). Las mediciones mandibulares incluyeron ancho bicondilar, ancho bigonial, ancho mínimo de la rama mandibular, longitud gonion- gnation, altura de la sínfisis mandibular y las dimensiones transversa y anteroposterior del cóndilo. Los datos obtenidos fueron sometidos a t test para muestras independientes con $p<0.05$ y análisis de la función discriminante con SPSS. La mayoría de las dimensiones fueron superiores en hombres que en mujeres, con excepción del ancho mínimo de la rama mandibular (0.2-0.16 $\mathrm{mm}$ ) y del diámetro transverso del cóndilo derecho $(0.16 \mathrm{~mm})$. El diámetro anteroposterior de la cabeza mandibular resultó la más dimórfica de las medidas analizadas, aunque ninguna diferencia resultó estadísticamente significativa. El análisis de la función discriminante indicó que a pesar de las diferencias, éstas no permiten clasificar de acuerdo al sexo en base a las variables cuantitativas analizadas. En conclusión, la mandíbula de niño en el primer año de vida presenta escaso dimorfismo sexual y no se recomienda el abordaje cuantitativo para la determinación del sexo con fines forenses.

Palabras clave: Dimorfismo sexual; Determinación del sexo; Subadultos; Mandíbula. 
SEX DETERMINATION USING MASTOID PROCESS MEASUREMENTS: STANDARDS FOR BRAZILIAN

SKULLS. Determinación del sexo usando mediciones en el proceso mastoids: estándares para cráneos brasileiros. Suazo G.I.C 1, 2; Zavando M.D.A1; Smith R.L2. 1Departamento de Anatomía Normal, Universidad de Talca 1Departamento de Morfología y Genética. Universidad Federal de Sao Paulo

Las características del proceso mastoides son de gran utilidad para el diagnóstico del sexo. De Paiva \& Segre (2003) describieron que era posible el diagnóstico del sexo en base a la determinación del área del triángulo formado entre los puntos Porion, Mastoidale y Asterion. El propósito de este estudio es evaluar la utilidad del método mediante análisis estadístico y de función discriminante. Se utilizaron 79 cráneos de individuos Brasileros, pertenecientes a la Colección de la UNIFESP, de sexo y edad conocidos, 49 hombres y 30 mujeres de entre 40 y 70 años (Media 51.58 años, DS 7.319). Todas las dimensiones fueron mayores en hombres que en mujeres, al analizarlas mediante $t$ test, sólo Porion-Mastoidale y el área resultó estadísticamente significativa $(p<0.01)$. De acuerdo al análisis de la función discriminante, la única dimensión que permite discriminar entre sexo fue PorionMastoidale. El porcentaje de cráneos correctamente clasificados resultó de un $74.1 \%$, con un $90 \%$ para hombres y sólo un $51.6 \%$ para mujer. Estos resultados nos indican que la determinación del sexo en base a las dimensiones del proceso mastoides tiende a subestimar a las mujeres, siendo de baja utilidad en la práctica.

Palabras clave: Dimorfismo sexual; Determinación del sexo; proceso mastoides; antropología Forense.

\section{THE RUDIMENTARY EYE OF THE FOSSORIAL REPTILE LEPOSTERNON INFRAORBITALE} (Amphisbenidae, Squamata). Foureaux, G.1; Gutierre, R. C. 1; Egami, M. I. 1; Jared, C. 2; Antoniazzi, M.M. 2; Curccio, D.1 ; Smith, R. L. 1 1Department of Morphology and Genetics, Universidade Federal de São Paulo (UNIFESP), São Paulo, Brasil 2Laboratory of Cellular Biology - Instituto Butantan, São Paulo, SP, Brasil

The low luminosity of some environments, such as the deep ocean, dark cavities and underground tunnels, propitiate the involution of the eye, which may become rudimentary, vestigial and even disappear.
Morphological studies of this rudimentary organ may consolidate the knowledge on its particular functions and evolutionary adaptations. Objective: to analyze the eye of the fossil reptile Leposternon infraorbitale. Methods: six specimens were provided by the Laboratory of Cellular Biology - Instituto Butantan. Euthanasia was performed by injecting a lethal dose of sodium thiopental $(30 \mathrm{mg} / \mathrm{Kg})$. The whole heads were fixed in Bouin's solution, decalcified in 7\% EDTA, phosphate buffer, $\mathrm{pH} 7.4$, in microwave for 3 days and embedded in paraffin for inspection under light microscopy; $4 \mathrm{~mm}$ sections were stained with three different methods: hematoxylin-eosin, modified Masson's Trichrome plus orcein and Kluver-Barrera. For the analysis under transmission electron microscopy, the eyes were removed, fixed with Karnovsky's solution and embedded in Epon resin. The thin sections were stained with $1 \%$ blue toluidine in sodium borate solution and were also observed under light microscopy. For the scanning electron microscopy analysis, sagittal sections of the head were fixed with Karnovsky's solution, following routine procedures. Electroretinography with needle-electrodes was performed in three animals. Results and Conclusion: the eyes presented a vesicular shape, similar to the optic cup. The three tunics could be observed. It was even possible to identify the three layers of the retina in the inner tunic. Screening electron microscopy revealed that the cornea is covered by a squamouslike epithelium and that the lens presents a vesicular aspect. The anatomical position of the eye may be related to its little functionality, since the scale that cover the eye precludes light penetration by dioptric means. On the other hand, the structure of the retina is still compatible with light perception and sensitivity, which indicates the necessity of other studies on brain projections and unicellular registers, to answer some questions on the biological role of the rudimentary eye.

Apoio financeiro: CAPES

TRATAMIENTO CON LÁSER INFRARROJO ASGA EN NERVIOS ISQUIÁTICOS LESIONADOS POR COMPRESIÓN, EN RATAS SPRAGUE DAWLEY. AsGa infrared laser treatment on isquiatic nerve crusch injured on Sprague Dawley rats. Matamala Fernando; Cornejo Ricardo; Vasconcellos Adriana; Paredes Marcos; Farfán Emilio;Maurelia Manuel. Departamento de Ciencias Básicas, Facultad de Medicina; Universidad de La Frontera. Temuco. Chile

La reparación de los nervios periféricos des- 
pués de un trauma es uno de los mayores desafíos de la medicina y microcirugía. Además, existe un interés creciente en las ciencias básicas para el estudio experimental, a fin de contribuir a buscar soluciones efectivas. Objetivos: 1. Determinar el efecto a nivel microscópico de la compresión del nervio isquiático de rata Sprague Dowley; 2. Evaluar la respuesta del tejido lesionado al tratamiento de fototerapia con láser infrarrojo de As $\mathrm{Ga}$, evaluando diversas tipos de dosis. Material y Método: Se utilizaron 5 ratas machos Sprague Dawley de un peso entre 250 y $300 \mathrm{~g}$ las que fueron anestesiadas con ketamina $(9 \mathrm{mg} / 100 \mathrm{~g}$ ) y cilazina $(1.25 \mathrm{mg} / 100 \mathrm{~g})$ y a las cuales se les aisló quirúrgicamente el nervio isquiático, el cual fue comprimido por $45 \mathrm{seg}$ con una pinza construida especialmente para la experiencia, con una fuerza constante de $40 \mathrm{~N}, 10 \mathrm{~mm}$ sobre la bifurcación en nervio tibial y nervio peroneal común. Una vez suturada y desinfectada la herida, 48 hrs después de esta acción, 2 ratas fueron irradiadas con un equipo láser de $\mathrm{AsGa}$ por un tiempo de 10 minutos y durante 10 dias con una potencia de $5 \mathrm{~mW}$. Otros 2 especímenes fueron irradiados con mayor potencia, $10 \mathrm{~mW}$, manteniendo iguales las otras variables de tratamiento con láser.

Posteriormente se eutanasiaron los animales con una sobredosis de anestésico y se extrajeron los nervios de las 4 ratas irradiadas y el de la rata control, los cuales fueron tratados con técnicas histológicas (HE; Van Giesonn y Luxol Fast Blue) y además de inmunohistoquímica para determinar el factor GAP-43. Se efectuó morfometría con software Kart Zeiss Axio Vision en cada nervio en estudio. Resultados: Se observaron diferentes respuesta del tejido lesionado en el tratamiento con láser, pues con la dosis bajas se comprobó una respuesta positiva en la reparación del tejidos demostrada a través de la comparación de los parámetros de razón G, células de Schawnn, fibroblastos y expresión del factor GAP-43.

Palabras clave: Neuropraxia; laser infrarrojo; reacción tisular.

Financiado por Proyecto DI08-0052 de la Dirección de Investigación y Desarrollo: Universidad de Frontera; Temuco, Chile

VARIACIONES ANATÓMICAS DEL CONDUCTO PAROTÍDEO. Lago E. M.; Lovato, Vanesa I.; Pozzi, G ; Encina, R. M. Director: Bergottini, C.H. Cátedra I de Anatomía Humana Normal e Imagenología. Profesor Civetta, J.D. Facultad de Medicina. U.N.N.E Corrientes.Argentina. Email: enriquemartinlago@hotmail.com
El conducto parotídeo de su nacimiento se proyecta en una línea que va desde el trago hasta el ala de la nariz, para terminar desembocando en la mucosa yugal a nivel del cuello del primer o segundo molar superior. El diseño es de tipo descriptivo. Se han utilizado 24 (veinticuatro) piezas cadavéricas adultas, de ambos sexos, formolizadas al $10 \%$. Se emplearon técnicas de disección y biometría clásicas e instrumentos convencionales. Los datos fueron tabulados, se aplicaron métodos estadísticos que fueron graficados. Se documentó fotográficamente en forma panorámica y focalizada. El material empírico observado señala, que las variantes más destacables se hallan a nivel del nacimiento de dicho conducto: Variedad 1 o clásica: se observa el nacimiento como tronco único presente en el $58.3 \%$ de los casos. Variedad 2: el nacimiento se da a través de dos ramas registrada en un $37.5 \%$ de los casos. Se presenta con más frecuencia en los cadáveres de sexo femenino. Variedad 3: el nacimiento es a partir de tres ramas, presente en el $2.4 \%$ de los casos. No se han observado variaciones del trayecto de acuerdo a lo comparado con el material tomado de referencia. De acuerdo a los datos de biometría obtenidos, el conducto presenta una longitud promedio desde su emergencia hasta su desembocadura de $7 \mathrm{~cm}$. y un diámetro medio de $8 \mathrm{~mm}$. Hemos corroborado la variabilidad en el conducto excretor de la glándula parótida en nuestro medio. Se ha producido un material de información básica para ser aplicado a la práctica clínico-quirúrgica y además se ha incrementado el número de piezas docentes de la cátedra..

Palabras clave: Conducto parotídeo. Variables. Glándulas Salivales.

VARIACIONES ANATOMICAS DEL TRONCO SIMPÁTICO CERVICAL. Anatomic variations of simphatetic cervical. Cabás Geat, Angeles E.; Naput, Maria P.; Ballesta D.; Mora, S. Director: Bergottini, C.H. Cátedra I de Anatomía Humana Normal e Imaginología. Prof. J. D. Civetta. Sargento Cabral 2001. CP 3400. Facultad de Medicina. UNNE. Corrientes. Argentina.

El presente trabajo acerca de las variaciones anatómicas del tronco simpático cervical se ha realizado con fines descriptivos para fundamentar la practica clínico-quirúrgica. Al recabar información bibliografíta respecto al tema se ha encontrado escasa referencia sobre su diversificación considerando la importancia que tiene la noción de su disposición al 
momento de su intervención en diversas patologías. El diseño es de tipo descriptivo. Se han utilizado treinta piezas cadavéricas adultas, de ambos sexos, formolizadas al $10 \%$. Se emplearon técnicas de disección y biometría clásica e instrumentos convencionales. Los datos fueron tabulados y se aplicaron métodos estadísticos que fueron graficados. Se documentó fotográficamente en forma panorámica y focalizada. El material empírico encontrado demuestra: La Variedad 1 que representa la deposición clásica en la cual los tres ganglios cervicales superior, medio e inferior se hallan presentes (Rouvière y Testu) tiene una frecuencia relativamente escasa. La variable 2 describe la fusión del ganglio cervical inferior con el primer torácico denominado ganglio estrellado (Rouvière y Testu) ocurre en la mayor parte de la muestra. La variable 3 es la agenesia del ganglio cervical medio que al igual que la anterior es muy frecuentemente observada. La variable 4 representa el desdoblamiento del cordón intermedio que abraza la arteria tiroidea inferior (Velayos) o a la arteria Subclavia (Bergman) en ausencia del ganglio medio. La variedad 5 en la cual el ganglio cervical medio se encuentra unido al polo inferior del ganglio cervical superior, denominado ganglio Cervical Medio de Swan o Krause (Bergman) se ha observado en una de las piezas cadavéricas. La Variable 6 y 7 representan a la existencia del ganglio cervical intermedio dentro de la arteria cervical y la fusión del ganglio cervical medio al inferior respectivamente. Estas dos son descriptas en la literatura y sigue siendo investigada su ocurrencia en nuestro medio. Se han cumplido con los objetivos del trabajo, ya que se ha producido un material de descripción básica acerca de la variabilidad de disposición anatómica del tronco simpático cervical para ser aplicado a la práctica clínica-quirúrgica de nuestra zona.

Palabras clave: Neurología. Tronco Simpático Cervical. Variables.

VARIACIONES EN EL ORIGEN DE LA ARTERIA MESENTÉRICA SUPERIOR Y SU CORRELACIÓN ANATOMO-RADIOLÓGICA. Variations on the origin of the superior mesenteric artery and its correlation anatomo-radiation. Arce, Yanina V.; Encinas Nuñez, C. G.; Almada Ruíz Díaz, Montserrat; Amarilla, J. C. Director: Dr. Harvey, W. Cátedra I de Anatomía Normal e Imagenología. Prof.: Dr. Civetta, J. D. Facultad de Medicina UNNE. Corrientes Argentina. Sargento Cabral 2001. CP: 3400.

E-mail: yaninavanesa_arce@hotmail.com
El conocimiento del origen de la arteria mesentérica superior (AMS), teniendo como referencia al tronco celíaco (TC) y los cuerpos vertebrales, es fundamental para planear y realizar los procedimientos quirúrgicos y radiológicos en el abdomen. Se utilizaron 30 imágenes en colores VR (Volumen Rendering) y en blanco y negro MIP (Máxima Intensidad de Proyección), obtenidos de un Tomógrafo Computado Volumétrico Multislice de 64 detectores con contraste yodado hidrosoluble inyectado con bomba de doble cabezal, adquiridos en tiempo arterial, obtenidos en el período del 2004 al 2007. Recurriéndose también a 6 piezas cadavéricas de adultos de ambos sexos fijadas en formol al $10 \%$, los mismos fueron disecados según los criterios establecidos por Testut, Jacob y Billet, empleándose material convencional con magnificación óptica de $2 X$ y $5 X$. Los datos se tabularon y analizaron estadísticamente. El diseño utilizado fue del tipo descriptivo. Los resultados obtenidos permitieron corroborar los datos descriptos en la literatura universal, en donde del $100 \%$ (36), el $41.67 \%$ (15) nació a nivel del borde inferior de L1, a 5-8 $\mathrm{mm}$ por debajo del origen del TC; el $25 \%$ (9) se originó a nivel de la porción media de L2, a 4-8 mm por debajo del origen del TC; el $11,11 \%$ (4) nació a nivel del disco intervertebral ubicado entre D12 y L1, a 7-9 mm por debajo del origen del TC; el $11,11 \%$ (4) se originó a nivel del borde superior de L1, a 6-10 mm del TC; y el 11,11\%(4) lo hizo a nivel del disco intervertebral situado entre L1 y L2, a 6-8 mm por debajo del TC. Este trabajo permitió corroborar que la Tomografía Volumétrica es un recurso fiel y confiable para fundamentar las prácticas clínico-quirúrgicas.

Palabras clave: Sistema Cardiovascular. Arterias. Abdomen. Mesentérica Superior. Variedades

Fuente de Financiamiento: Facultad de Medicina de la UNNE

VARIEDADES DE PRESENTACIÓN DEL MÚSCULO CORACOBRAQUIAL. Gómez, Claudia L.; Salvatierra, Brenda; Passarino, G.A; Gonzáles Luque Mariana. Director: Dr. Bergottini, C. H. Cátedra I de Anatomía Humana Normal e Imagenología Dr. Civetta, J.D. Universidad Nacional del Nordeste. Facultad de Medicina. UNNE. Sargento Cabral 2001.C.P: 3.400. Corrientes, Argentina.

email:dianamezdo@hotmail.com

El músculo coracobraquial (CB), flexor principalmente, es un músculo que pertenece al plano muscular profundo del brazo solo por su parte inferior. Se en- 
cuentra en la parte superomedial del brazo, se extiende desde el proceso coracoides a la cara medial del húmero, está perforado por el nervio musculocutáneo generalmente. Su acción es dirigir el brazo hacia delante y adentro. Debido a las distintas actividades que realiza diariamente el hombre en el ámbito rural, como lo es el nuestro, se observa una gran incidencia de lesiones en la musculatura del miembro superior, por ello hemos decidido realizar este trabajo haciendo énfasis en las variables de presentación y de la morfología de la unidad de análisis. Para así fundamentar las prácticas clínico-quirúrgicas en nuestros servicios de salud. El diseño utilizado es de tipo descriptivo. Se utilizaron 30 piezas cadavéricas adultas de ambos sexos fijadas en formaldehído al $10 \%$ que fueron abordadas por las vías de disección convencionales e instrumental clásico y con magnificación óptica de 2 X y 5x. Realizándose su registro y posterior documentación en fotografías panorámicas y focalizadas, los datos obtenidos fueron tabulados y se utilizaron técnicas estadísticas. Resultados: Del total de piezas analizadas, 13, 33\% (4 piezas) presentaron variaciones anatómicas: Variedad I: Clásica (Rouvière): $86,67 \%$ (26 piezas): el C.B. se origina proximalmente en el proceso coracoide por un tendón común con la cabeza corta del músculo bíceps braquial. Atraviesa la axila y termina por un tendón en la cara medial del húmero. Cerca de la mitad de su trayecto está dividido en dos fascículos, por un intersticio, que es por donde el nervio musculocutáneo lo atraviesa. Variedad II: (Bergman I): 13,33 \% (4 piezas): el haz carnoso del músculo coracobraquial no es atravesado por el nervio músculo cutáneo. Variedad III: (Bergman II): 0\%: (0 piezas): la porción distal del músculo coracobraquial está representada por una extensión proximal originada en el cuello quirúrgico del húmero o en la cápsula de la articulación del hombro o por una cabeza accesoria (Coracobraquial Superior o Brevis). Variedad IV: (Word): 0\%: (0 piezas): la porción distal puede presentarse como músculo coracobraquial inferior o largo unido al húmero, o al septum intermuscular medial (ligamento de Struthers) o al epicóndilo medial. Variedad V: (Mori): 0\%:(0 piezas): el haz carnoso de C.B. se encuentra separado en toda su longitud en dos haces, uno superficial y otro profundo. Variedad VI: (Mori II): 0\%:(0 piezas): Un haz carnoso perteneciente a la porción distal del C.B. se dirige hacia la porción terminal del músculo pectoral mayor. Conclusiones: Consideramos que hemos llegado a los objetivos propuestos, demostrando que la variabilidad de presentación del objeto de estudio es escasa en nuestra región, además se ha producido material útil que fundamenta las prácticas clínicas- quirúrgicas y material pedagógico para la docencia.
VARIEDADES DE PRESENTACIÓN DEL MÚSCULO DELTOIDES. Señuk Valeria E., Wolhein Mariela V., Rogosinski Paola O., Rusnok Florencia E. Universidad Nacional del Nordeste. Facultad de Medicina. Director/a: Gómez Claudia. Cátedra I de Anatomía Humana Normal e Imagenología. UNNE. Sargento Cabral 2008 Corrientes, Argentina.

e-mail: valeria_s01@hotmail.com

El músculo deltoideo cubre la articulación escápulo humeral. Tiende a estabilizar el hombro, ayudando a mantener la cabeza del húmero dentro de la cavidad glenoidal de la escápula durante los movimientos del mismo. Nuestro objetivo es estudiar el referido músculo, su morfología y variedades de presentación, en función de las prácticas clínicas-quirúrgicas. Siendo la región del Nordeste Argentino una zona Agrícola ganadera, son muy frecuentes las lesiones del miembro superior. Se utilizaron 37 (treinta y siete) piezas cadavéricas adultas de ambos sexos, fijadas en formol al 10\% empleándose material convencional de disección y microdisección e instrumentos de magnificación óptica. Se documentó con fotografías panorámicas y focalizadas y se tabularon los datos obtenidos realizándose inferencias estadísticas. La observación del material empírico muestra: Variedad 1: Clásica (Rouviere): Se origina en el tercio lateral del borde anterior y cara superior de a clavícula. Vértice y borde lateral del acromion. Vértice inferior del borde posterior de la espina de la escápula. Se fija en la tuberosidad deltoidea del húmero. Se registraron en un $64.86 \%$. Variedad 2: Basio Deltoidea (Mackelli); Fascículo que se origina en la fascia del músculo infraespinoso. Se fija en el borde posterior del fascículo clavicular del M. deltoide. Se registraron en un $2.70 \%$. Variedad 3: Costodeltoideo (Calori); Fascículo que se origina en el borde axilar de la escápula y/o fascia del músculo infraespinoso. Se fija entre los M. deltoideo y triceps braquial. Se registraron en un $0 \%$. Variedad 4 : Acromioclavicular lateral (Gruber); Fascículo que se origina en el acromion. Se fija en el fascículo clavicular del músculo deltoide. Se registraron en un $0 \%$. Variedad 5: fascículos que se originan en el borde espinal de la escápula. Se fijan en la parte dorsal del M. deltoide. Se registraron en un $0 \%$. Variedad 6 : (Macalister); Los fascículos claviculares, acromiales y espinosos pueden mantener independencia. Se registraron: haz espinal $24.32 \%$, haz clavicular $5.40 \%$, haz acromial $0 \%$, los tres haces separados $5.40 \%$. Variedad 7: (Testut Latarget); La inserción distal puede darse a diferentes alturas. Se registraron: Alta 18.91\%, Clásica o media $73.25 \%$, Baja $7.84 \%$. El material empírico demuestra la escasa variabilidad del múscu- 
lo deltoides en el nordeste argentino conformándose una información básica útil para las practicas clínicas quirúrgicas de la zona, asimismo se ha producido material cadavérico pedagógico para el uso docente de la cátedra.

\section{VARIEDADES DE PRESENTACIÓN DEL MÚSCULO} TRÍCEPS BRAQUIAL. Gómez, Claudia L. ; Correa, Gabriela A. ; Popelka, Paula ; Rivelli, Agostina M. Director: Dr. Bergottini, C. H Cátedra I de Anatomía Humana Normal e Imagenología Dr. Civetta, J.D. Universidad Nacional del Nordeste. Facultad de Medicina. UNNE. Sargento Cabral 2001.C.P: 3.400. Corrientes, Argentina. email:dianamezdo@hotmail.com

El siguiente trabajo considera como unidad de análisis al músculo tríceps braquial (T.B), siendo sus variedades de presentación, su trayecto y relaciones las variables de estudio. El músculo tríceps braquial es un músculo que se encuentra en la región posterior del brazo extendiéndose desde el escapular y el húmero hasta el olécranon. Está dividido por arriba en tres porciones: la cabeza larga se extiende hasta la escápula, las otras dos, cabeza lateral y cabeza medial, se insertan en el húmero. Las variables detectadas en el marco teórico están referidas a la cabeza larga del T.B. Por las frecuentes patologías que afectan en nuestra región agrícola ganadera, a los músculos del miembro superior, hemos decidido analizar, describir y tipificar sus características morfológicas y sus variedades de presentación del T.B, a fin de fundamentar las prácticas clínico-quirúrgicas. Este trabajo es de tipo descriptivo. Se utilizaron treinta y siete piezas cadavéricas adultas de ambos sexos fijadas con formol al 10\%, empleándose técnicas y material convencional de disección y micro disección e instrumentos de magnificación óptica de $2 x$ y $5 x$. Se documentó con fotografías panorámicas y focalizadas, se tabularon los datos obtenidos aplicándose los niveles de medición propios de las variables estudiadas y las técnicas estadísticas correspondientes. El total de piezas anatómicas analizadas muestra lo siguientes: Variedad I o Clásica (Rouviere-Testut) 62,16\% (23 piezas): El T.B. se extiende desde la escápula y el húmero al olécranon. Las cabezas terminan en un tendón común que se inserta en la cara superior del olecranon y por dos expansiones laterales en sus bordes. Variedad II (Macalister I) 0\% (0 piezas): Un tendón de unión desde el borde inferior del músculo latísimo del dorso a la cabeza larga del músculo T.B. Variedad III (Macalister II) 2,70\% (1 pieza): Un haz carnoso conectado con las fibras costales del músculo latísimo del dorso a la cabeza larga. Variedad IV (Harrison) 0\% (0 piezas) El T.B. ocasionalmente pude estar unido al ancóneo. Variedad V (Gruber) 0\% (0 piezas): Un haz carnoso desde la cabeza larga del músculo tríceps braquial al proceso coracoides (cabeza adicional). Variedad VI (Macalister III) 2,70\% (1 pieza): Un haz carnoso para el músculo subescapular. Variedad VII (Macalister IV) 0\% (0 piezas) Un pequeño haz conectado con la cápsula del hombro que continua por encima de la cavidad glenoidal. Variedad VIII (Macalister V) 0\% (0 piezas) Una doble cuarta cabeza, una del proceso coracoides y otra de la cápsula. Variedad IX (Jenty) $0 \%$ (0 piezas): Fusión de la cabeza lateral con el origen del extensor del carpo. Consideramos que hemos alcanzado los objetivos fijados, ya que se produjo material de información básica para sustentar las prácticas clínico quirúrgicas, demostrando la escasa variabilidad existente en nuestro medio del T.B.y a la vez la necesidad de realizar un estudio a nivel nacional.

\section{VARIATIONS OF INTERNAL ANATOMY OF INFE- RIOR PREMOLARS ARE OF CLINICAL INTEREST.}

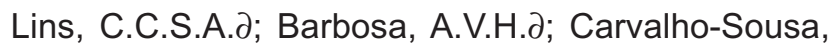

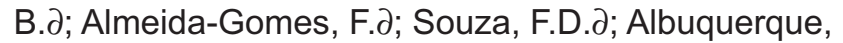

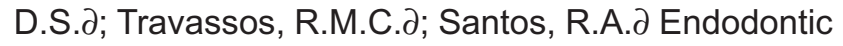
Departament, UPE-FOP, Recife, Pernambuco, Brazil.

In order to obtain success in the endodontic treatment, the Dental Surgeon needs to know the anatomy and internal morphology of root canal to realize a correct cleaning, molding and obturation of the system of root canals. Among the different dental groups, the inferior premolar is described as a uniradicular tooth which has only one canal, although some studies showed that these teeth can have many variations. Methods and Results: The aim of this work was to show, by periapical radiographies obtained from patients of the in Clinic of Curse the Endodontics Especialization Faculdade de Odontologia de Pernambuco - University of Pernambuco, the year of 2007 , five kinds of variations found in this tooth: presence of two canals, bifurcation, trifurcation, recurrent canal and apical delta, approaching its radiographic morphological characteristics as well as the suitable treatment. Conclusion: This way, we want to emphasize that, so the clinicians as the specialists need to be prepared to recognize these variations and can have success with the treatment. 


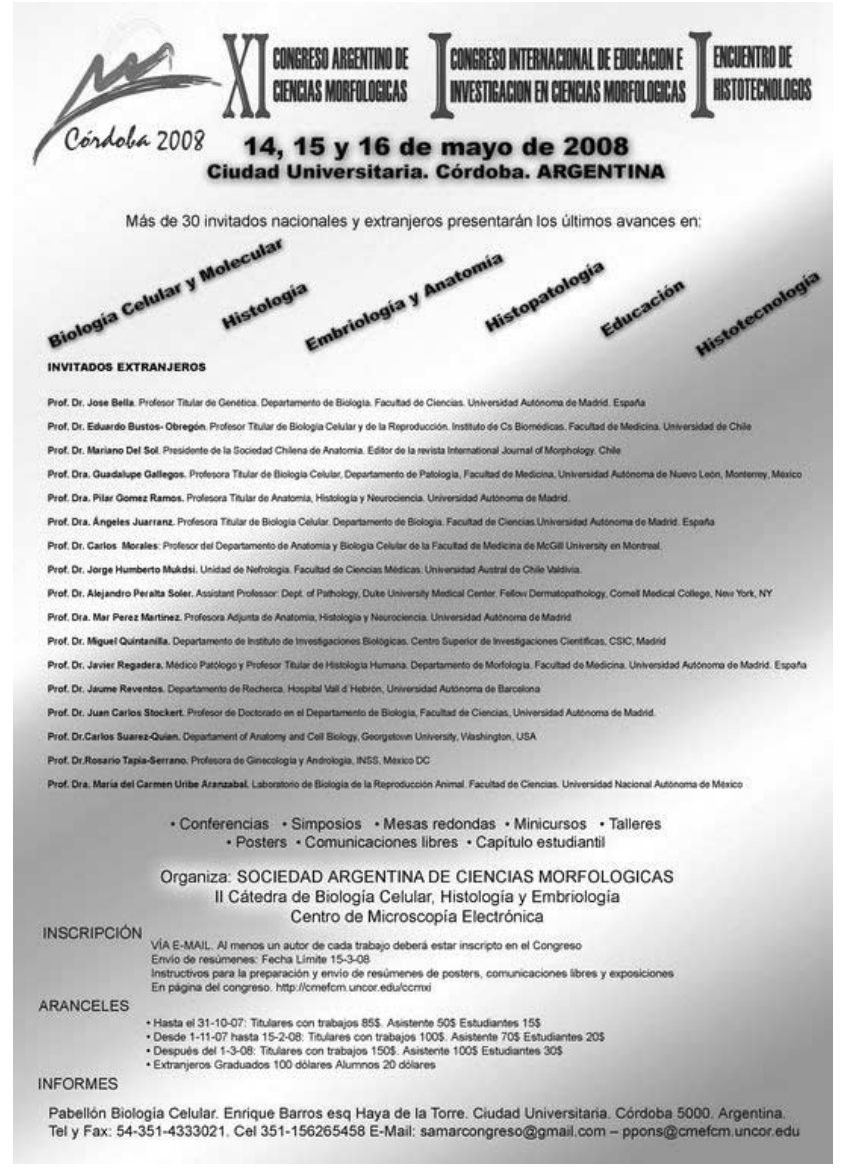

C-KIT POSITIVE CELLS IN THE BOWEL OF THE HORSE.

Células c-kit Positivas en el Intestino Delgado del Equino Galotta JM1, Márquez SG1,2; Gálvez GA2; Portiansky EL3, Barbeito CG3, 4. 1Fac. Ciencias Agrarias UCA; 2CBC, UBA 3Instituto de Patología, 4 Cátedra de Histología y Embriología. Fac. Ciencias Veterinarias UNLP. Freire 183. CP1426.Buenos Aires.Email:jorge.galotta@gmail.com

The interstitial cells of Cajal (ICC) are involved in the control of intestinal motility and act as a pacemaker regulating the slow waves. ICC are generally located next to the myenteric plexus (stomach, intestine, small intestine, large intestine), in the inner surface of the round smooth muscle layers of the colon, in the deep muscular plexus of the small intestine and within the layers of round smooth muscle and longitudinal smooth muscle alongside the intestine. This work describes the distribution pattern of ICC in the horse small intestine using immunohistochemical techniques. Samples of duodenum, jejunum and ileum were obtained from healthy adult horses at commercial abattoirs. Tissue samples were included in paraffin and cut at 4-5 $\mu \mathrm{m}$ thick slices. Slides were incubated with polyclonal anti c-kit antibodies (CD117) or with monoclonal anti-vimentine or antidesmine antibodies. Using optic microscopy different positive c-kit cell populations were observed. In all the observed slides c- kit immunostained cells were always detected in a close proximity to the myenteric plexus; they also showed a regular continuous distribution around the ganglionic cells. Besides, positive cells were found within the muscular layers. In the duodenum, they were located among the muscle fibres of the inner round smooth muscle layer. In the ileum they were in groups inside the longitudinal layer of muscular coat. The anti-vimentine and anti-desmine antibodies were useful to identify connective and muscular tissue, respectively. The positive c-kit cells were also stained with anti-vimentine antibody. Taking into account the location, the spindle shaped aspect of the cells, the connection with the myenteric plexus, the specificity of the anti c-kit immunostaining and the previous bibliographical data, we are able to conclude that the studied cells are ICC.

Key words: Interstitial Cells of Cajal; c-kit; small intestine, horse.

Financial supported by Pontificia Universidad Católica Argentina and UBACYT V403.

EL LIBRO VIRTUAL VS. EL LIBRO EN LÍNEA (EL DILEMA DE LA DISPERSIÓN) Virtual Book Vs. Online Book (The Dilemma of Multiple Paths). Sabbatino VE, Lassalle AN, Márquez SG. Departamento de Biología. Ciclo Básico Común. UBA. E-mail: genomasur@yahoo.com

Hoy resulta redundante mencionar la riqueza de información o recursos que nos ofrece Internet, así como los infinitos recorridos que nos posibilita. En tanto internautas, sería absurdo renegar de ello. Sin embargo, el dilema se nos presenta a la hora de confeccionar un instrumento para nuestros alumnos. ¿Siempre resulta útil una hoja de ruta en blanco? Como docentes nos vemos en la necesidad de elaborar material hipertextual que cumpla con varios requisitos: contenidos adecuados al programa, al cronograma, al nivel del curso y a la idiosincrasia del alumnado, incorporando la mayor cantidad de TICs posible. Para lograrlo optamos por elaborar un mapa de rutas. Nuestra propuesta es un libro virtual. Tal herramienta presenta los contenidos organizados a partir de una red conceptual, que conduce a contenidos mínimos jerarquizados, animaciones y actividades de evaluación. Esta propuesta es factible de ser colgada en la red y almacenada en CD para su distribución. La diferencia entre el libro virtual y el libro en línea radica en la menor dispersión que ofrece el primero, pues los enlaces a los que remite forman un circuito cerrado en si mismo. Así, el alumno tiene la libertad de alterar el orden dentro de un universo menor, garantizando la adquisición de los contenidos mínimos. El material al que nos referimos 
está destinado a un curso introductorio al nivel universitario, en el cual es fundamental propiciar la adquisición y/o práctica de una metodología de estudio, formativa para el futuro del estudiante. Actualmente el docente universitario se ve obligado a tomar en cuenta su rol formativo, especialmente en cursos introductorios, si es que busca eficacia en su labor. Debe asumir necesariamente que su tarea no termina al finalizar la clase. Es en este sentido en el que cobran importancia herramientas tales como la propuesta que nos ocupa.

Palabras clave: Internet; Hipertexto; TICs; Libro Virtual; Libro en Línea; Educación No Presencial.

\section{ONTOGENIC STUDIES OF THE INTERSTITIAL CELLS} OF CAJAL IN THE BOVINE STOMACH COMPARTMENTS. Estudio de las Células Intersticiales de Cajal del Estómago a lo largo del Desarrollo Ontogénico Bovino. Márquez SG1,2,Galotta JM1, Gálvez GA2, Portiansky EL3, Barbeito CG3,4.1Fac. Ciencias Agrarias, UCA; 2CBC, UBA; 3Instituto de Patología, 4Cátedra de Histología y Embriología, Fac. Ciencias Veterinarias,UNLP. Freire 183.CP1426.Buenos Aires.Email: silviamarquez@gmail.com

Interstitial cells of Cajal (ICC) are involved in the regulation of the gastrointestinal tract motility. In this study, the presence, distribution and morphology of ICCs of the bovine stomach were compared through three life stages: foetal (5-month gestation), young (one week old) and adult (more than four years old). Samples of rumen, reticulum, omasum and abomasum from six animals of each age group were processed. Immunohistochemistry with anti-c-kit/CD117 antibodies was carried out to specifically identify ICC. These cells were observed among the muscle fibres of all the gastric chambers in all the analysed stages. Foetal and calf slides showed a bigger immunostaining area in comparison to adults. This data would be coherent with the decrease of the numbers of ICC per unit surface while growing older. In the foetus and calf, ICC can be seen as a network given that they connect each other through their long prolongations, but in the adult these cells are isolated. Considering the three studied periods, the ICC of the abomasum are placed alongside the myenteric plexus where they surround the ganglionic cells and the muscularis mucosae. In the adult rumen, ICC are seen in the myenteric plexus, but in the foetus and the calf they are uniformly distributed in the muscular layers. In the reticulum of foetus and calf, a great amount of positive cells can be seen in the tunica muscular, in the myenteric plexus and in the axis of the crests. In the omasum of foetus and calf, a lot of bipolar ICC are observed in both muscular layers. These results show the presence of c-kit positive ICC in foetus and young animals. Besides they can support the hypothesis that in the bovine stomach, the ICC/muscle fibres ratio decreases along ontogeny and that ICC loose some of the primitive position.

Key words: Interstitial Cells of Cajal; c-kit; bovine; ontogeny; stomach.

Financial supported by UBACYT V403 and Pontificia Universidad Católica Argentina.

MÉTODO HOLÍSTICO Y CAÓTICO EN LA ENSEÑANZA DE ANATOMÍA. Wílson de Mello Júnior - Dept. de Anatomía - Instituto de Biociências - Universidade Estadual Paulista - UNESP/Botucatu - SP - Brasil

En la enseñanza de Anatomía Humana fue comparada la utilizaron de dos métodos distintos: método tradicional (descriptivo o topográfico) y el método holístico, caracterizado por método no reduccionista, deductivo, caótico, basado en los principios de los pensamientos sistémico y complejo. Entre 2003 y 2007, durante los cursos de Anatomía Humana para alumnos del primer año de Graduación en Ciencias Biomédicas, con 120 horas presenciales, se combinaran clases y evaluaciones tradicionales con holísticas (integradas). Posiblemente debido a su elevada preparación preuniversitaria, comprobada por riguroso examen de selección de ingreso en la Universidad, los alumnos no tuvieron dificultades para aprobar la asignatura independientemente del método aplicado. El método tradicional se caracterizó por el estudio progresivo, independiente y planificado de los sistemas orgánicos. Los alumnos que siguieron este método obtuvieron un buen rendimiento académico, pero presentaron dificultades de integración y de asociación de la información aprendida, dando respuestas caracterizadas por la disociación de las ideas y los elementos. El método holístico se caracterizó por el estudio simultáneo e integrado de los sistemas orgánicos, de acuerdo con los intereses de los alumnos, abordando el organismo como un todo, sin división en regiones, sin una planificación cronológica fijada, sólo teniendo un eje directivo (se utilizó el sistema nervioso como guía). Con este método, se consiguió un mejor rendimiento de los alumnos utilizando evaluaciones tradicionales y de las percepciones integradas. De manera que, se puede concluir que el éxito académico (superación de la asignatura) fue independiente del método de enseñanza utilizado; aunque el método holístico amplia la capacidad de percepción de las conexiones y relaciones organísmicas, facilitando la interdisciplinaridad y la transdisciplinaridad, garantizando un aprendizaje significativo y en consecuencia una mejor formación profesional y humana. 